UNIVERSIDADE DE SÃO PAULO

NARA ANGÉLICA POLICARPO

TRATAMENTO DE SOLOS CONTAMINADOS COM BIFENILAS POLICLORADAS (PCBS) 
NARA ANGÉLICA POLICARPO

\title{
TRATAMENTO DE SOLOS CONTAMINADOS COM BIFENILAS POLICLORADAS (PCBS)
}

\begin{abstract}
Dissertação apresentada à Escola Politécnica da Universidade de São Paulo para obtenção do Título de Mestre em Engenharia
\end{abstract}

São Paulo 


\section{TRATAMENTO DE SOLOS CONTAMINADOS COM BIFENILAS POLICLORADAS (PCBS)}

Dissertação apresentada à Escola Politécnica da Universidade de São Paulo para obtenção do Título de Mestre em Engenharia

Área de Concentração:

Engenharia Química

Orientador: Prof. Dr. Cláudio Augusto Oller do Nascimento 


\section{FICHA CATALOGRÁFICA}

\section{Policarpo, Nara Angélica}

Tratamento de solos contaminados com bifenilas policloradas (PCBs) I N.A. Policarpo. -- São Paulo, 2008.

$$
\text { p.72 }
$$

Dissertação (Mestrado) - Escola Politécnica da Universidade de São Paulo. Departamento de Engenharia Química.

1. Solos contaminados (Remediação) 2. Oxidação química 3. Reagente de fenton I. Universidade de São Paulo. Escola Politécnica. Departamento de Engenharia Química II. t. 
À mainha por todo o esforço e amor dedicado à minha educação. 


\section{AGRADECIMENTOS}

Ao amigo e engenheiro da Lubnor, João Augusto, que possibilitou o contato com o meu orientador, e por isso, permitiu que eu desenvolvesse esse trabalho.

Ao Prof. Dr. Claudio Nascimento pela orientação e apoio.

Ao Prof. Dr. José Ermírio pela co-orientação e disponibilidade incondicionais.

À FUSP e ao CNPq, que através do Departamento de Engenharia Química da POLI/USP, financiaram a pesquisa.

Ao Grupo de Pesquisas em Separações por Adsorção (GPSA) da Universidade Federal do Ceará (UFC) pela realização das análises das amostras de solo.

A Deus que sempre esteve comigo em todos os momentos da minha vida.

À mainha e My que sempre estiveram ao meu lado me incentivando com seu amor.

A Gerby, Gil, Helena e Thiago que se tornaram a minha segunda família, dando força nos momentos difíceis.

A todos os meus amigos pela força e amizade, sem a qual eu não viveria. Em especial a James, Flávia, Denise, Beatriz, Ayres e Vanio.

Aos queridos amigos "viciados em volei" do CEPE pelos divertidos momentos, especialmente Marcelo.

Àqueles que contribuíram de alguma forma para a execução desse trabalho. 
Para cada esforço disciplinado há uma retribuição múltipla. Jim Rohn 


\section{RESUMO}

Devido à alta toxicidade, a produção e comercialização dos PCBs (Polychlorinated Biphenyls - Bifenilas Policloradas) estão proibidas no mundo todo. Esses compostos foram utilizados principalmente como base de misturas comerciais em óleos dielétricos para transformadores e capacitores. Hoje existem diversas áreas contaminadas com essas substâncias que são de difícil degradação ocasionada pela sua elevada estabilidade térmica e química. Há diversos estudos sobre diferentes técnicas de tratamento de áreas contaminadas por PCBs. A técnica proposta nesse trabalho foi a de oxidação química através do reagente de Fenton. Para isso, foi simulado em laboratório experimentos de tratamento de solo contaminados artificialmente por ascarel (mistura comercial de PCBs). A oxidação foi realizada segundo a técnica do planejamento experimental fatorial de dois níveis e duas variáveis. Manteve-se constante a concentração do contaminante - em torno de $6000 \mathrm{mg}$ de $\mathrm{PCB} / \mathrm{kg}$ de solo - e variou-se a concentração de $\mathrm{Fe}^{2+}(0,04$ a 0,1 $\mathrm{mol} / \mathrm{L})$ e $\mathrm{H}_{2} \mathrm{O}_{2}(2,07$ a $4,15 \mathrm{~mol} / \mathrm{L})$. Os ensaios foram realizados ainda nos seguintes tempos de reação: $0,5,24$ e 48 horas. A análise dos dados foi realizada através de cromatografia gasosa acoplada a um espectrômetro de massa - GC/MS. Dos resultados, concluiu-se que o experimento cuja concentração do reagente de Fenton era $4,15 \mathrm{~mol} / \mathrm{L}$ de $\mathrm{H}_{2} \mathrm{O}_{2}$ e $0,04 \mathrm{~mol} / \mathrm{L}$ de $\mathrm{Fe}^{2+}$, apresentou melhor percentual de remoção, em torno de $76 \%$ para o pentaclorobifenila, $67 \%$ para o hexaclorobifenila e $72 \%$ para o heptaclorobifenila. Além disso, observou-se que, dentro da região experimental estudada, o efeito da concentração de íons ferrosos foi mais significativo do que o causado pela concentração de peróxido de hidrogênio e que o mesmo tem um efeito negativo pois aumentando a concentração dos íons ferrosos diminui-se a remoção dos contaminantes.

Palavras-chave: Solos. Bifenilas Policloradas. Reagente de Fenton. 


\begin{abstract}
Production and trading of polychlorinated biphenyls (PCBs) are prohibited at whole world due to their high toxicity. They were used mainly as dielectric oils for transformers and capacitors. Recently there are many contaminated areas with these compounds. The high thermic and chemistry stability of PCBs are responsible for their hard degradation. Many studies have been conducted about several techniques of soil remediation. The main purpose of this research is to study chemical oxidation using Fenton's reagent to soils treatment. It was simulated in laboratory experiments of soil treatment which was artificially contaminated with Ascarel (PCBs commercial mixture). Process oxidation was made according to factorial experimental planning technique of two levels and two variables $\left(2^{2}\right)$. The contaminant concentration was constant $-6000 \mathrm{mg} \mathrm{PCB} / \mathrm{kg}$ soil - and it was varied the $\mathrm{Fe}^{2+}$ concentration $(0,04$ $\mathrm{mol} / \mathrm{L}$ to $0,10 \mathrm{~mol} / \mathrm{L})$ and $\mathrm{H}_{2} \mathrm{O}_{2}$ concentration $(2,07 \mathrm{~mol} / \mathrm{L}$ to $4,15 \mathrm{~mol} / \mathrm{L})$. The times reaction of experiments were: $0,5,24$ and 48 hours. It was used gas chromatography coupled with mass spectrometer - GC/MS. The better result shown removal rate of $76 \%$ to pentachlorobiphenyl, $67 \%$ to hexachlorobiphenyl and $72 \%$ to heptachlorobiphenyl, experimental conditions were $\mathrm{Fe}^{2+}$ concentration of $0,04 \mathrm{~mol} / \mathrm{L}$ and $\mathrm{H}_{2} \mathrm{O}_{2}$ concentration of $4,15 \mathrm{~mol} / \mathrm{L}$. Besides it was observed that studied region the concentration effect of ferrous ions was more significant than concentration effect of hydrogen peroxide. The concentration effect of ferrous ions was negative on system because removal rate of contaminants decreases when $\left[\mathrm{Fe}^{2+}\right]$ increases.
\end{abstract}

Keywords: Soils. Polychlorinated Biphenyls. Fenton's Reagent. 


\section{LISTA DE FIGURAS}

Figura 1: Relação de áreas contaminadas no Estado de São Paulo (CETESB, 2007)

Figura 2: Grupos de contaminantes encontrados nas áreas contaminadas no Estado de São Paulo (CETESB, 2007) 20

Figura 3: Fórmula estrutural dos PCBs 24

Figura 4: Comportamento de contaminante orgânico em subsolo (Costa et al., 1999)

Figura 5: Estrutura molecular de uma dioxina e de um furano (Mesquita, 2004) .....31

Figura 6: Equipamento Autosorb da Quantachrome para determinação de área superficial específica (BET).

Figura 7: Células de reação

Figura 8: Extrator Soxhlet da TECNAL.

Figura 9: Extrator Soxhlet da Gerhardt.

Figura 10: Vial para análise cromatográfica do extrato .40

Figura 11: Cromatógrafo da Shimadzu utilizado nas análises das amostras .... 41

Figura 12: Cromatograma típico dos PCBs .42

Figura13: Amostra de solo utilizado nos experimentos 43

Figura 14: Extração dos congêneres de PCBs (pentaclorobifenila, hexaclorobifenila e heptaclorobifenila) ao longo do tempo de extração .50

Figura 15: Intensidade dos picos de PCBs na extração em solo úmido. 51

Figura 16: Intensidade dos picos de PCBs na extração em solo seco .51

Figura 17: Áreas dos picos para os congêneres penta, hexa e heptaclorobifenila resultantes da extração da amostra úmida com diferentes solventes - hexano, hexano/acetona e etanol

Figura 18: Áreas dos picos para os congêneres penta, hexa e heptaclorobifenila resultantes da extração da amostra seca com diferentes solventes - hexano, hexano/acetona e etanol

Figura 19: Áreas dos picos para os congêneres hexa e heptaclorobifenila resultantes da extração das amostras seca e úmida com diferentes solventes hexano, hexano/acetona e etanol 
Figura 20: Degradação do hexaclorobifenila, com 24 h de reação e diferentes quantidades de $\mathrm{H}_{2} \mathrm{O}_{2}$ e $\mathrm{Fe}^{2+}$ 56

Figura 21: Degradação dos congêneres penta, hexa e heptaclorobifenila com 5, 24 e 48 horas de reação e 2,07 mol/L de $\mathrm{H}_{2} \mathrm{O}_{2}$ e $0,04 \mathrm{~mol} / \mathrm{L}$ de $\mathrm{Fe}^{2+}$ .57

Figura 22: Planejamento experimental fatorial de dois níveis e duas variáveis $\left(2^{2}\right) .58$

Figura 23: Gráfico de barras dos efeitos das variáveis e suas interações para o pentaclorobifenila 60

Figura 24: Percentual de remoção de congêneres de PCBs em 48 horas de reação nas condições F, G, H e I do planejamento experimental

Figura 25: Percentual de remoção dos congêneres de PCBs no experimento na condição do ponto central para 48 horas de reação

Figura 26: Modelos 1, 2 e 3 propostos para ajuste dos dados do pentaclorobifenila

Figura 27: Modelos 1, 2 e 3 propostos para ajuste dos dados do hexaclorobifenila 67 Figura 28: Modelos 1, 2 e 3 propostos para ajuste dos dados do heptaclorobifenila 67

Figura 29: Superfície de resposta referente ao pentaclorobifenila .68

Figura 30: Superfície de resposta referente ao hexaclorobifenila 68

Figura 31: Superfície de resposta referente ao heptaclorobifenila 69 


\section{LISTA DE TABELAS}

Tabela 1: Alguns nomes comerciais dos PCBs (Ambicare, 2005) ........................22

Tabela 2: Distribuição dos congêneres de PCBs $\left(\mathrm{C}_{12} \mathrm{H}_{10-z} \mathrm{Cl}_{z}\right)$ (Rice et al., 2003) ....23

Tabela 3: Grau de cloração dos possíveis congêneres de PCBs (adaptado de

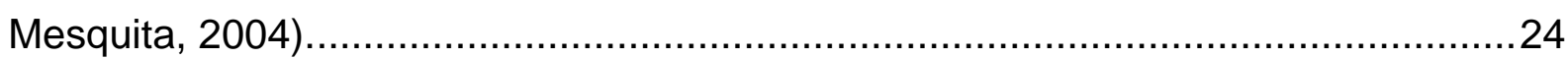

Tabela 4: Dados referentes ao cálculo da umidade do solo ...............................45

Tabela 5: Dados referentes ao cálculo do teor de orgânicos do solo ....................46

Tabela 6: Características texturais do solo .................................................. 47

Tabela 7: Dados experimentais do ensaio de tempo de extração ........................49

Tabela 8: Parâmetros adotados para a extração dos PCBs em solo para três

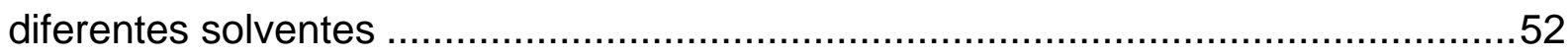

Tabela 9:Variáveis absolutas e normalizadas do planejamento experimental.........59

Tabela 10: Resultados do planejamento experimental ...................................59

Tabela 11: Percentuais de remoção na condição experimental do ponto central para os três congêneres (penta, hexa e heptaclorobifenila) 62

Tabela 12: Percentuais de remoção experimental e calculados para o pentaclorobifenila

Tabela 13: Percentuais de remoção experimental e calculados para o hexaclorobifenila .65

Tabela 14: Percentuais de remoção experimental e calculados para o heptaclorobifenila 65 


\section{SUMÁRIO}

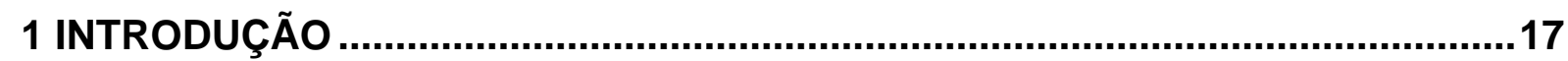

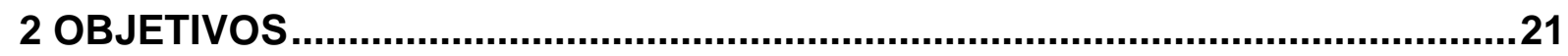

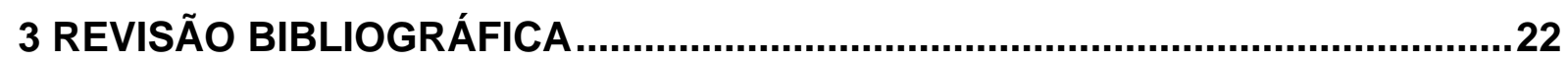

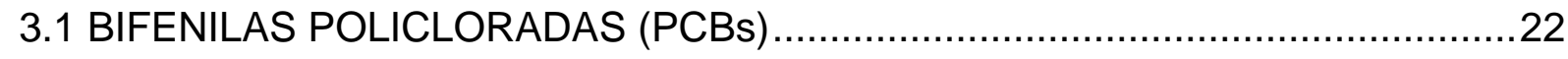

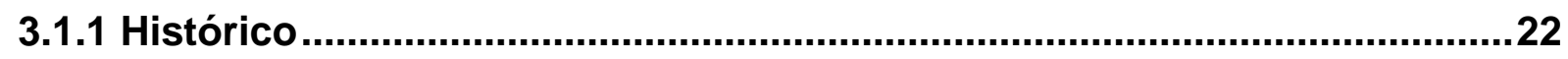

3.1.2 Características Físico-Químicas ...........................................................23

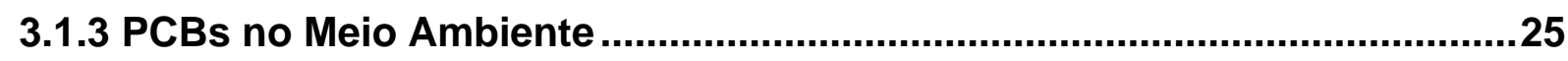

3.1.4 Legislação Específica para os PCBs .....................................................26

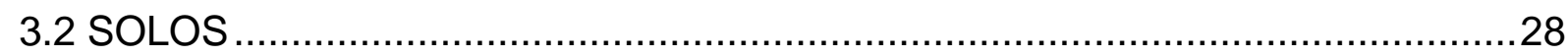

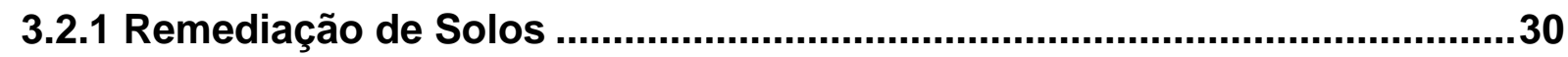

3.2.1.1 Remediação de Solos Contaminados por PCBs .......................................... 31

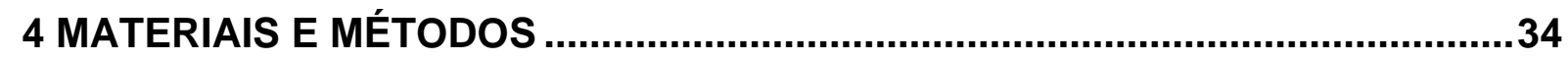

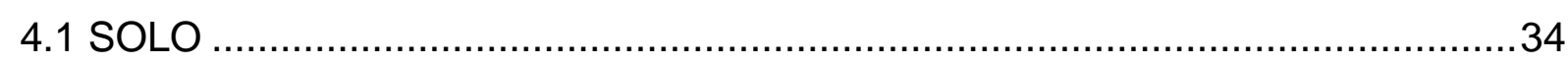

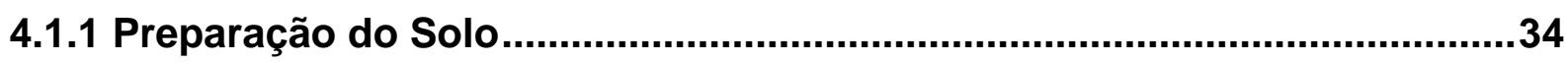

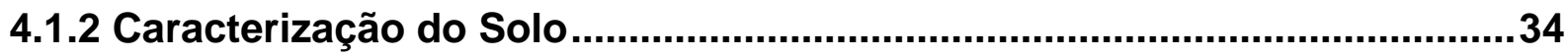

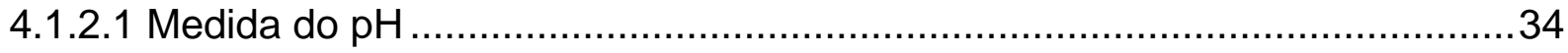

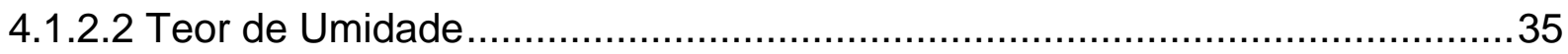

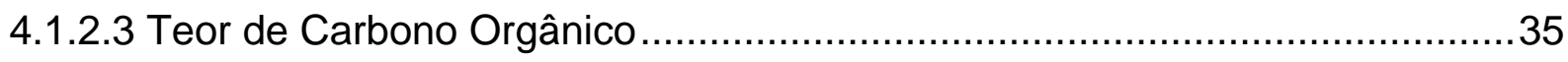

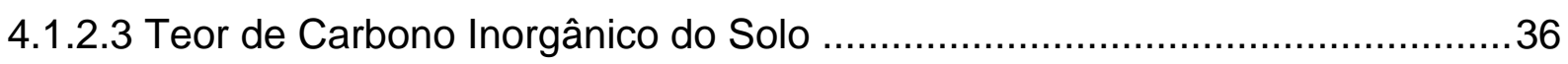

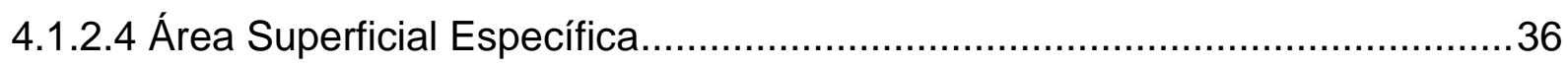

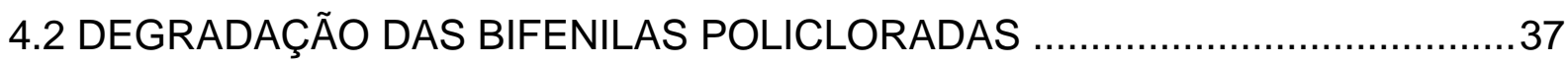

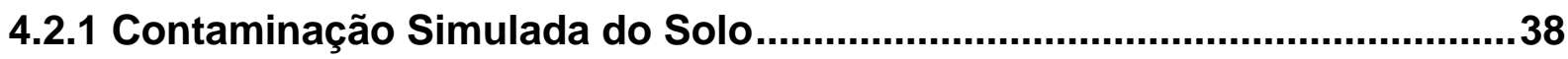

4.2.2 Oxidação com o Reagente de Fenton..........................................................38

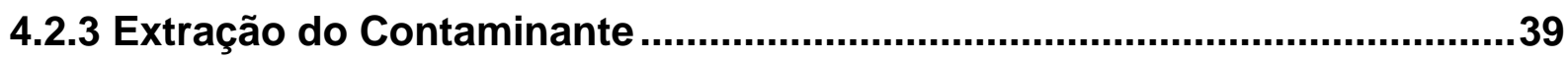

4.2.3 Cromatografia Gasosa / Espectrômetro de Massa (CG/MS)......................41

5 RESULTADOS E DISCUSSÃO

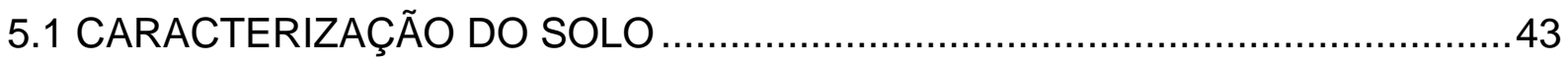

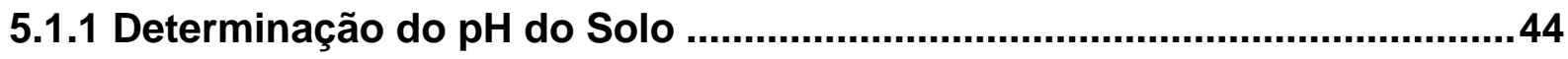

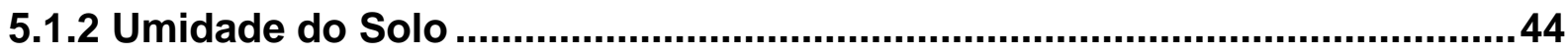

5.1.3 Determinação do Teor de Orgânicos do Solo.............................................45

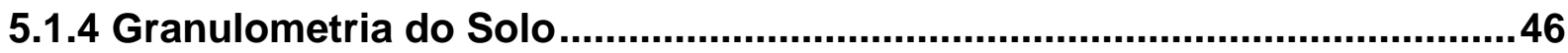


5.1.5 Área Superficial Específica ......................................................................46

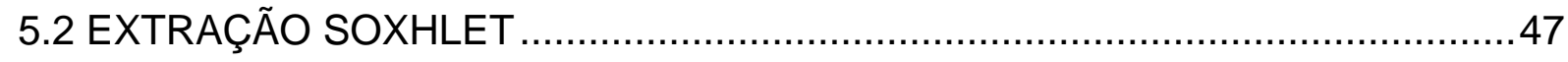

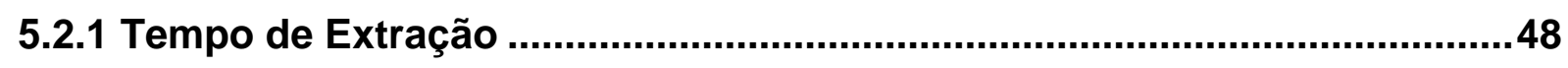

5.2.2 Influência da Umidade na Extração ......................................................50

5.2.3 Teste de Solventes de Extração............................................................. 52

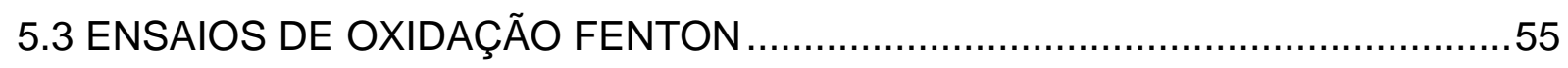

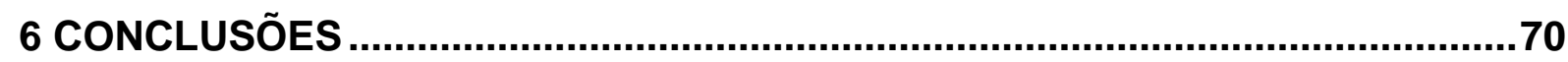

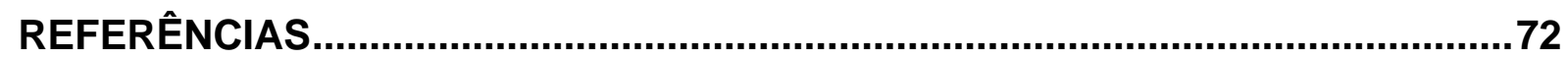




\section{INTRODUÇÃO}

A revolução industrial ofereceu a sociedade incontáveis benefícios, mas trouxe consigo vários inconvenientes, dentre eles a contaminação maciça do meio ambiente por substâncias nocivas para a saúde do planeta e de todos os seres vivos.

Várias são as substâncias maléficas aos seres vivos e ao ambiente, mas algumas delas têm destaque devido à sua alta toxicidade, são os chamados Poluentes Orgânicos Persistentes (POPs). Fazem parte desse grupo 12 compostos: dioxinas, furanos, bifenilas policloradas (PCBs), hexaclorobenzenos (HCBs), aldrin, dieldrin, endrin, clordano, toxafeno, mirex, dicloro-difenil-tricloroetano (DDT) e heptacloro.

Os POPs são compostos orgânicos sintéticos altamente estáveis, semivoláteis, gerados intencionalmente ou não e surgem através de diversos processos industriais, entre eles (Greenpeace, 2005):

- Produção do cloreto de polivinila (PVC): plástico utilizado em embalagens de alimentos, brinquedos, utensílios domésticos, tubos e conexões, etc.;

- Produção de papel: através do processo de branqueamento com cloro;

- Geração e composição de produtos agrícolas: um grande número de herbicidas, inseticidas e fungicidas;

- Incineração de lixo: doméstico, industrial e hospitalar;

- Processos industriais: todos os que empregam cloro e derivados de petróleo.

Quando esses contaminantes orgânicos e seus subprodutos atingem o meio ambiente - através de transformações físicas, químicas e biológicas - eles sofrem processos de volatilização, biodegradação, transferência para organismos, ligações entre as partículas do solo e percolação para o lençol freático (Mesquita, 2004). Sabe-se que os POPs percorrem longas distâncias através da atmosfera pois foram encontrados em lugares remotos do globo terrestre (regiões polares) que nunca entraram em contato com tais substâncias (Breivik et al., 2004). Por causa disso, a eliminação desses compostos é um problema de caráter mundial.

Nesse contexto, para ratificar a proibição do uso dos POPs e sua redução no meio ambiente, vários países assinaram o acordo proposto pela Convenção de 
Estocolmo sobre Poluentes Orgânicos Persistentes realizada em 2001 (UNEP, 2006).

Estima-se que, dos POPs estocados, mais de um milhão de toneladas sejam de PCBs distribuídos globalmente. Não há estimativas sobre o quanto dos solos e sedimentos contaminados está associado a esses estoques existentes de PCBs (Greenpeace, 1998). Inúmeros são os episódios de contaminação de solos por bifenilas policloradas em todo o mundo, alguns dos quais estão ilustrados a seguir.

Em 1998, a Eletropaulo transferiu um de seus imóveis localizado na Zona Sul de São Paulo para a Empresa Metropolitana de Águas e Energia (Emae). No referido imóvel, a Eletropaulo armazenava óleo ascarel (mistura comercial de PCBs) em galões dentro do terreno. Por causa disso, o óleo infiltrou no terreno contaminando cerca de 21 mil $\mathrm{m}^{2}$ de solo (Baeta, 2003).

Um estudo de caso apresentado por Leuser et al. (1990) relata o tratamento de 8500 toneladas de solos contaminados com PCBs no estado americano de Illinois. Na área contaminada existiam cerca de 400 transformadores e mais de 75 capacitores abandonados e, dentre eles, alguns apresentavam vazamento de óleo à base de PCBs.

A contaminação do ar, da água e do solo tem sido causa de preocupação constante já há alguns anos por parte da sociedade e governos. A poluição da água e do ar é um problema que já possui uma legislação bem definida. Porém, o problema da contaminação do solo vem recebendo atenção nos últimos anos. Alguns países do mundo já possuem uma legislação específica para tais situações. Entre elas as mais conhecidas são a americana e a holandesa que servem de modelo para vários países que ainda não possuem legislação para amparar tais casos. No Brasil, o problema ainda não possui legislação específica. Isso fica claro no trecho do artigo escrito por Gabeira (2003):

Uma série de denúncias sobre áreas contaminadas pela indústria ou mineração acabou inspirando o trabalho da Comissão de Meio Ambiente. Ao invés de fazer uma lei, estudaram-se as principais áreas (Santo Amaro, na Bahia, e Cidade dos Meninos, em Duque de Caxias, RJ). O resultado foi uma pressão sobre o governo para que formulasse uma política de descontaminação. 
Apesar do país não possuir leis regulamentadoras específicas para o controle e remediação de áreas contaminadas, já existem iniciativas pontuais para sanar esses problemas, é o caso da Companhia de Tecnologia de Saneamento Ambiental (CETESB) ligada à Secretaria de Meio Ambiente do Estado de São Paulo. Esse órgão é responsável pela fiscalização, monitaramento e licensiamento das atividades que geram poluição, tentando preservar a qualidade do meio ambiente. Aplicando diferentes técnicas de remediação, esse órgão ambiental tem efetuado diversas atividades de recuperação de algumas das áreas contaminadas (ACs) existentes no Estado. Vale destacar que, das técnicas de remediação aplicadas para solos, as mais utilizadas pela CETESB são a extração de vapores e a remoção do solo/resíduo (CETESB, 2006).

De 2002, data da primeira divulgação pela CETESB, até o último relatório de novembro de 2007, o número de áreas contaminadas aumentou de 255 para 2.272, somente no Estado de São Paulo. Das áreas contaminadas cadastradas, apenas 94 tem remediação concluída, 884 tem remediação iniciada, 146 tem proposta de remediação em andamento e 1.148 não possuem sequer proposta de tratamento. A Figura 1 mostra um gráfico da evolução ao longo dos anos das áreas contaminadas do Estado de São Paulo (CETESB, 2007).

Dos grupos de contaminantes, encontram-se solventes aromáticos e/ou halogenados, metais, combustíveis e hidrocarbonetos aromáticos policíclicos (PAHs), como pode ser visto na Figura 2. Vale destacar que, do total de áreas contaminadas no estado, 21 estão contaminadas por bifenilas policloradas (PCBs) (CETESB, 2007).

Ao redor do mundo, o número de áreas contaminadas é alarmante e poucos são os países que possuem esses dados contabilizados. Alguns números de ACs no mundo são: cerca de 60.000 na Holanda (VROM, 2007), até 2001 eram 55.000 na Alemanha (UMWELTBUNDESAMT, 2006), 3.500 na França (CETESB, 2007) e até 2000 eram 63.000 nos Estados Unidos (ELI, 2001). 


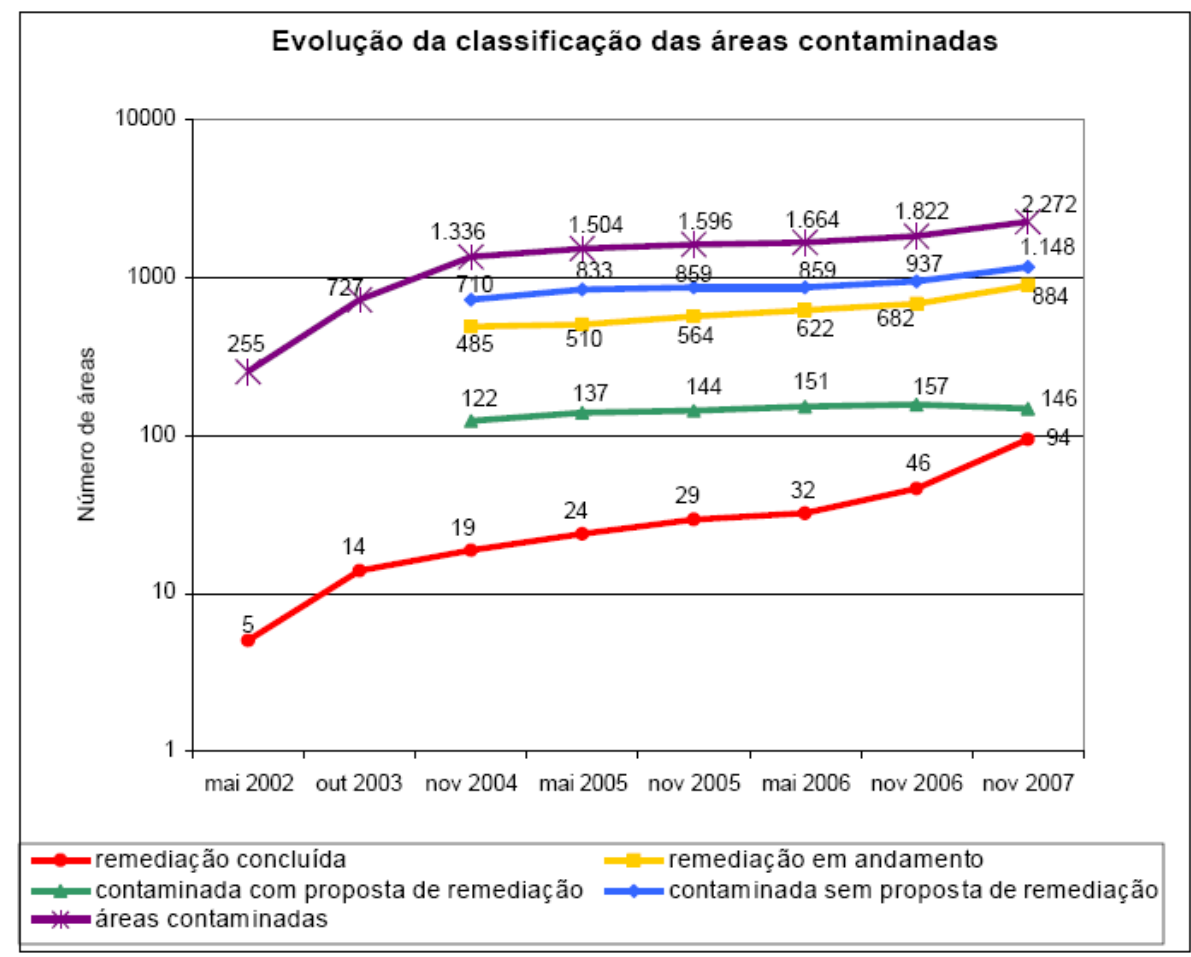

Figura 1: Relação de áreas contaminadas no Estado de São Paulo (CETESB, 2007)

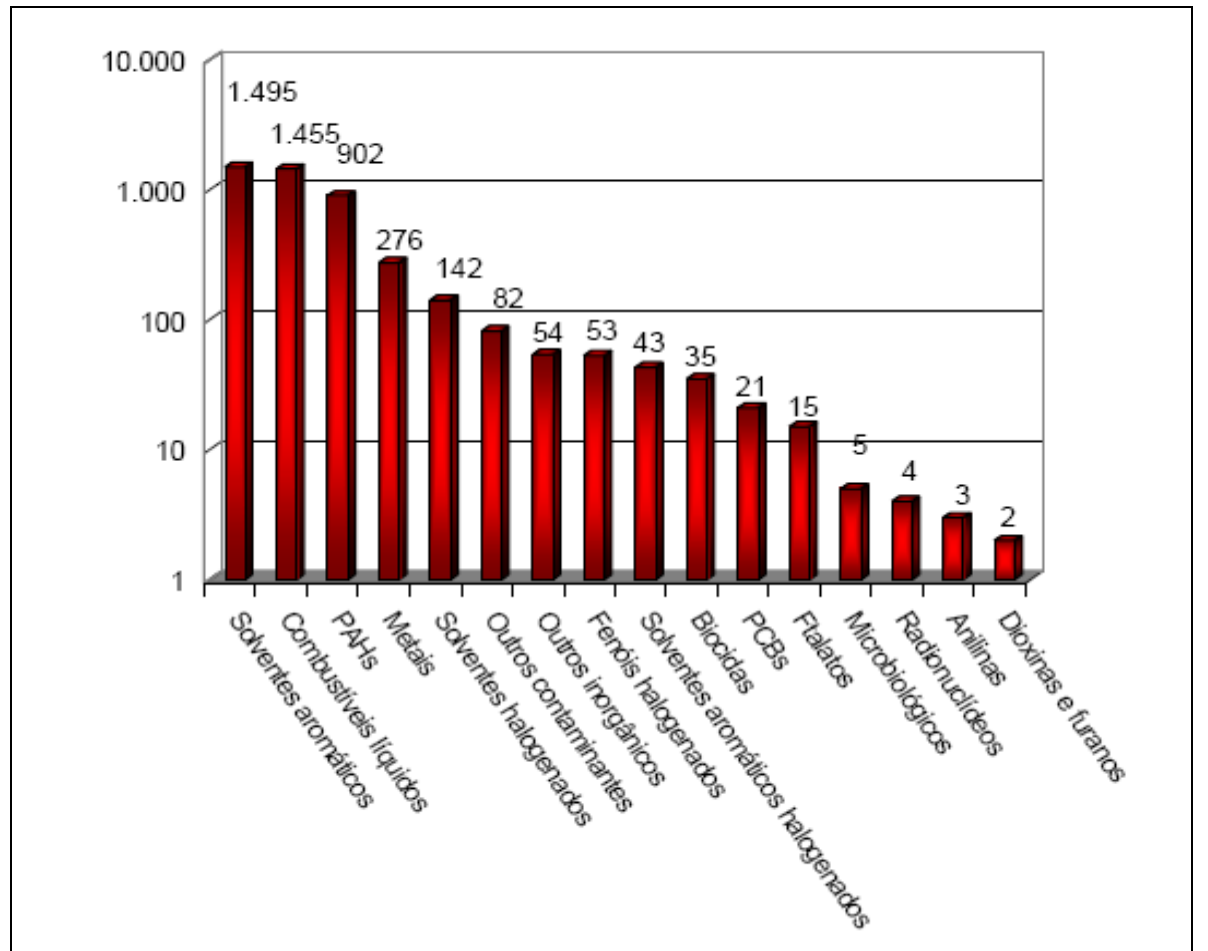

Figura 2: Grupos de contaminantes encontrados nas áreas contaminadas no Estado de São Paulo (CETESB, 2007) 


\section{OBJETIVOS}

Diante do exposto, o objetivo geral deste trabalho é estudar o tratamento de solos contaminados por bifenilas policloradas utilizando o processo de oxidação química avançada denominado Fenton.

Para compreender melhor a dinâmica do sistema solo-contaminante-oxidante, pretende-se propor uma metodologia experimental, em escala de laboratório, para a degradação desse contaminante em solo. Como a metodologia inclui diversas etapas, tem-se que compreender na íntegra todas elas.

A etapa primordial é a de oxidação do contaminante em solo. Para tal, utilizou-se o Reagente de Fenton. Nesses experimentos, pretendeu-se estudar a influência da concentração dos reagentes de Fenton (peróxido de hidrogênio e sal de ferro) sobre o sistema além do tempo de reação.

Uma outra etapa é a extração do contaminante após a oxidação do mesmo. Essa etapa torna-se fundamental no procedimento pois se a mesma não for eficiente irá causar erros grosseiros na quantificação da degradação do poluente. Além disso, a extração por solventes têm sido uma técnica usada há algum tempo tanto em escala comercial como em laboratório como alternativa de tratamento de solos contaminados por contaminantes orgânicos. Por isso, foram feitos alguns de extração enfatizando dois pontos:

1) o tempo de extração, ou seja, o tempo ótimo em que se obtém o máximo de contaminante extraído do solo;

2) e o tipo de solvente (polar e apolar)

Definida uma metodologia experimental adequada, quantificou-se relativamente a degradação do contaminante e com isso foi possível dar um parecer sobre a viabilidade técnica do processo. 


\section{REVISÃO BIBLIOGRÁFICA}

\subsection{BIFENILAS POLICLORADAS (PCBS)}

\subsubsection{Histórico}

As bifenilas policloradas (Biphenyl Polychlorinated - PCB) são substâncias que foram sintetizadas pela primeira vez antes da virada do século $X X$ - por volta de 1881 - por Schmidt e Schulz, mas só em 1929 começaram a ser produzidas em escala industrial (Tanabe, 1988). O crescimento da produção ocorreu devido à necessidade de se encontrar um óleo de resfriamento e isolante estável e eficiente para equipamentos elétricos. Dessa forma, o pico de produção ocorreu em 1970 com um volume de 50.000 toneladas (Penteado e Vaz, 2001). Em 1966, o químico suíço Soren Jansen determina que os PCBs são um contaminante ambiental e desde então a utilização dos mesmos começou a ser restringida no mundo todo (Wikipédia, 2005).

Para fins práticos, os PCBs foram misturados com outros fluidos (carrier fluids) tais como clorobenzenos ou óleo mineral (Kueper et al., 2003). Dessa forma, dependendo do país onde eram fabricados ou comercializados, essas misturas receberam uma denominação (Tabela 1).

Tabela 1: Alguns nomes comerciais dos PCBs (Ambicare, 2005)

\begin{tabular}{ccc}
\hline Marca & Fabricante & País de Origem \\
\hline Aroclor & Monsanto & EUA \\
Piranol & General Eletric & EUA \\
Clophen & Bayer & Alemanha \\
Aceclor & ACEC & Bélgica \\
Piroclor & Monsanto & Reino Unido \\
Kaneclor & Kanegafuchi/Mitsubichi & Japão \\
Piralene & Prodelec & França \\
Phenoclor & Prodelec & França \\
\hline
\end{tabular}


Não existem registros de produção de PCBs no Brasil. Todo o PCB existente no país foi importado dos Estados Unidos e da Alemanha. Ascarel é o nome comercial do produto usado no Brasil e é constituído, aproximadamente, de $75 \%$ do Aroclor 1254 e 25\% de triclorobenzeno (Antonello et al., 2005).

Por várias décadas esses compostos foram usados como fluido de troca térmica em trocadores de calor, lubrificantes em equipamentos hidráulicos e principalmente como óleos dielétricos em transformadores e capacitores elétricos (USEPA, 2000). De forma menos intensa, eles ainda estiveram presentes na formulação de adesivos, tintas, pesticidas, corantes e graxas (Borja et al., 2005).

\subsubsection{Características Físico-Químicas}

Bifenila policlorada (Biphenyl Polychlorinated - PCB) é o nome genérico de uma classe de hidrocarbonetos aromáticos clorados que formam, teoricamente, um conjunto de 209 compostos químicos diferentes (Tabela 2), chamados de congêneres, cuja fórmula é $\mathrm{C}_{12} \mathrm{H}_{(10-z)} \mathrm{Cl}_{z}$, onde $\mathrm{z}=\mathrm{x}+\mathrm{y}$, variando de 1 a 10. A Figura 3 mostra a fórmula estrutural dos PCBs.

Tabela 2: Distribuição dos congêneres de PCBs $\left(\mathrm{C}_{12} \mathrm{H}_{10-z} \mathrm{Cl}_{z}\right)$ (Rice et al., 2003)

\begin{tabular}{cc}
\hline Homólogo & Possíveis Congêneres \\
(Baseado no número de cloros) & 3 \\
\hline Monocloro- & 12 \\
Dicloro- & 24 \\
Tricloro- & 42 \\
Tetracloro- & 46 \\
Pentacloro- & 42 \\
Hexacloro- & 24 \\
Heptacloro- & 12 \\
Octacloro- & 3 \\
Nonacloro- & 1 \\
Decacloro- & $\mathbf{2 0 9}$ \\
\hline TOTAL &
\end{tabular}




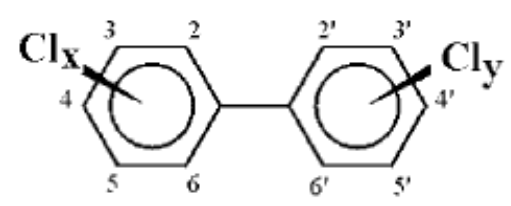

Figura 3: Fórmula estrutural dos PCBs

Todo o PCB existente no mundo foi sintetizado, não existindo, portanto, fontes naturais dessas substâncias (Rahuman et al., 2000). De forma resumida, o processo de síntese de uma molécula de PCB consiste na formação da bifenila pela desidrogenação de duas moléculas de benzeno a $800^{\circ} \mathrm{C}$ seguido da cloração do núcleo de bifenila com cloro gasoso anidro a $100^{\circ} \mathrm{C}$ catalisado por cloreto férrico ou limalha de ferro. A reação ocorre com aumento do volume de massa da mistura devido ao incremento na concentração do cloro. Quando esse volume atinge o teor de cloro desejado, a reação é interrompida (Mesquita, 2004). A Tabela 3 mostra características dos possíveis congêneres de PCBs de acordo com o grau de cloração.

Tabela 3: Grau de cloração dos possíveis congêneres de PCBs (adaptado de Mesquita, 2004).

\begin{tabular}{l|ccc}
\hline Fórmula Estrutural & Grau de Cloração & $\begin{array}{c}\text { Massa Molecular } \\
\text { (g/mol) }\end{array}$ & Cloro (\%) \\
\hline $\mathrm{C}_{12} \mathrm{H}_{9} \mathrm{Cl}_{1}$ & 1 & 188,65 & 18,79 \\
$\mathrm{C}_{12} \mathrm{H}_{8} \mathrm{Cl}_{2}$ & 2 & 233,10 & 31,77 \\
$\mathrm{C}_{12} \mathrm{H}_{7} \mathrm{Cl}_{3}$ & 3 & 257,54 & 41,30 \\
$\mathrm{C}_{12} \mathrm{H}_{6} \mathrm{Cl}_{4}$ & 4 & 291,99 & 48,56 \\
$\mathrm{C}_{12} \mathrm{H}_{5} \mathrm{Cl}_{5}$ & 5 & 326,43 & 54,30 \\
$\mathrm{C}_{12} \mathrm{H}_{4} \mathrm{Cl}_{6}$ & 6 & 360,88 & 58,93 \\
$\mathrm{C}_{12} \mathrm{H}_{3} \mathrm{Cl}_{7}$ & 7 & 395,32 & 62,77 \\
$\mathrm{C}_{12} \mathrm{H}_{2} \mathrm{Cl}_{8}$ & 8 & 429,77 & 65,98 \\
$\mathrm{C}_{12} \mathrm{H}_{1} \mathrm{Cl}_{9}$ & 9 & 464,21 & 68,73 \\
\hline $\mathrm{C}_{12} \mathrm{Cl}_{10}$ & 10 & 498,66 & 71,10 \\
\hline
\end{tabular}

Os PCBs existem na forma de líquidos (óleos) e sólidos (resinas/graxas), com a cor variando de incolor a amarelo claro. Não possuem sabor nem cheiro. São compostos de elevada estabilidade térmica e química, baixa pressão de vapor a temperatura ambiente e alta constante dielétrica - o que possibilitou o uso intenso 
em equipamentos elétricos. São insolúveis em água, porém extremamente solúveis em óleos vegetais, gorduras animal e em solventes orgânicos (Borja et al., 2005).

Por causa dessas características, os PCBs são compostos altamente resistentes à degradação e uma vez liberados no ambiente, tendem a se acumular nos organismos e também a se biomagnificar ao longo da cadeia alimentar. São altamente tóxicos à saúde humana e provocam diversas doenças tais como: câncer, problemas reprodutivos, neurológicos, dermatológicos e endócrinos (são conhecidos como disruptores endócrinos) (Vorhees, 2004; Penteado, 2000).

\subsubsection{PCBs no Meio Ambiente}

O uso freqüente dos PCBs aliado à práticas inadequadas de manuseio, além de acidentes industriais, resultaram na crescente contaminação do ar, da água e do solo por esses compostos.

Segundo Rahuman et al. (2000), os PCBs podem percorrer longas distâncias quando entram em contato com o ar e ali permanecerem por aproximadamente 10 dias. Esse fato é comprovado pela presença desses compostos em regiões polares como o Ártico e que nunca estiveram em contato com esse tipo de produto. No ar, eles aparecem tanto na forma gasosa como na particulada (Vorhees, 2004). Muitos trabalhos abordam essa problemática seja na forma experimental, como no trabalho de Eckhardt et al. (2007), ou simulada como em García-Alonso e Pérez-Pastor (2003).

Quando se trata de água e solo, o problema fica intimamente ligado, pois quando uma quantidade de PCBs atinge uma fonte de água somente uma pequena quantidade é dissolvida, o resto fica aderido a partículas orgânicas, sedimentos e animais aquáticos (Kile et al., 1995). Os PCBs são altamente adsorvidos no solo, ligando-se à matéria orgânica, devido à sua alta hidrofobicidade e baixa volatilidade. Por isso, acredita-se que não haja migração de PCBs para áreas distantes da fonte de contaminação (Sedlak e Andren, 1994). Inúmeros são os casos relatados em todo o mundo de contaminação de cursos de água (Penteado, 2000) e solos por PCBs (Backe et al., 2004), concentrados principalmente em regiões industrializadas. 


\subsubsection{Legislação Específica para os PCBs}

As primeiras preocupações com o controle da produção e utilização dos PCBs só surgiram depois da ocorrência de alguns acidentes que causaram a contaminação do meio ambiente e de seres humanos. O primeiro acontecimento relatado aconteceu em 1966 na Suécia com a morte de uma águia sem causa aparente (Ambicare, 2005). Embora o caso tenha ocorrido na Europa, foram nos EUA, em 1978, que surgiram as primeiras leis regulamentadoras sobre o uso dessas substâncias (Penteado e Vaz, 2001).

No Brasil, a regulamentação somente se deu em 1981 com a aprovação da Portaria Interministerial $\mathrm{n}^{\circ} 19$ entre o Ministério do Meio Ambiente, IBAMA e o Ministério de Minas e Energia. Essa portaria proibe a produção e comercialização da substância no país mas não exige a substituição de equipamentos elétricos que estejam em bom funcionamento e que ainda utilizem óleo isolante a base de PCBs (Luna e Braga, 1997). Em 1986 é decretada a Norma ABNT/NBR-8371 que estabelece orientações para o manuseio, acondicionamento, rotulagem, armazenamento, transporte, procedimentos para equipamentos em operação e eliminação dos PCBs. Em 2002, a Resolução no 313 do CONAMA obriga às concessionárias de energia elétrica apresentaram aos Órgãos Estaduais de Meio Ambiente um inventário do seu estoque de PCBs (PNUMA/UNEP, 2006). No Estado de São Paulo foi promulgada recentemente a Lei $\mathrm{n}^{0} 12.288$ de 22 de fevereiro de 2006. Essa Lei regulamenta a eliminação controlada dos PCBs e dos seus resíduos -considerando como tal qualquer material que contenha teor da substância acima de $50 \mathrm{mg} / \mathrm{kg}$ - a descontaminação e a eliminação dos equipamentos elétricos que contenham PCBs, e dá providências correlatas. A Lei determina ainda que os equipamentos elétricos que contenham PCBs e que estejam em uso sejam eliminados até dezembro de 2020 (TECORI, 2006). Portanto, para os PCBs, a legislação existente é específica somente no que se refere à destinação dos equipamentos elétricos e manuseio da substância em si.

Quanto à regulamentação de áreas contaminadas só existem algumas medidas que abordam o problema indiretamente e propostas em tramitação. Por exemplo, a Lei Estadual no 13.564 de abril de 2003 em São Paulo determina que, 
antes da construção de novos empreendimentos em áreas contaminadas ou suspeitas de contaminação, o local deverá passar por uma avaliação técnica para a detecção da possível contaminação (ABETRE, 2004). Ainda nesse contexto, também no Estado de São Paulo, a CETESB é o único órgão ambiental licenciado para o gerenciamento de áreas contaminadas no país até o momento.

Nesse sentido, as legislações mundiais de caráter preventivo e corretivo mais forte são a dos Estados Unidos, Alemanha e Holanda. Nos Estados Unidos foi criado, em 1980, um programa chamado de Superfund a partir do decreto Comprehensive Environmental Response, Compensation, and Liability Act (CERCLA). O programa tem como objetivo aplicar ações corretivas sobre as áreas contaminadas, dando prioridade para aquelas áreas cadastradas na National Priorities List (NPL), as quais precisam de uma medida urgente de remediação (USEPA, 2005). Seguido dos Estados Unidos vem a legislação holandesa. De acordo com Mesquita (2004), os valores orientadores para intervenção de área contaminada por PCBs, segundo a Norma Holandesa, são:

- $\quad$ 0,2 mg/kg, em peso seco, para solo com 0\% de argila e 0\% de matéria orgânica;

- $\quad 1,0 \mathrm{mg} / \mathrm{kg}$, em peso seco, para solo com $25 \%$ de argila e $10 \%$ de matéria orgânica.

Os valores orientadores para solos adotados pela CETESB para bifenilas policloradas são mais rigorosos que os aplicados pela Norma Holandesa. Tais valores estão listados abaixo (CETESB, 2005).

- Prevenção: 0,0003 mg/kg de solo seco;

- Intervenção: 0,01 mg/kg de solo seco em área agrícola, 0,03 mg/kg de solo seco em área residencial e 0,12 mg/kg de solo seco em área industrial.

Para finalizar, a ausência de legislação específica de controle dos estoques de PCBs no Brasil reflete na inexistência de inventários contabilizando a quantidade desses compostos. O que existem são estimativas, e estas mostram que devam existir em torno de 68.000 toneladas de PCBs no país (PNUMA/UNEP, 2006). 


\subsection{SOLOS}

O impacto da contaminação no solo não é tão óbvio. Por muito tempo o solo foi considerado um local seguro para a disposição de lixo e também um local onde a degradação de contaminantes ocorria naturalmente. Por causa da sua capacidade de armazenamento (buffer) e baixa velocidade no transporte de substâncias, passaram-se alguns anos sem que houvesse notícia sobre os efeitos maléficos da contaminação do solo (Otten et al., 1997).

Sparks (2003) define o solo como uma mistura heterogênea composta de ar, água, sólidos orgânicos, sólidos inorgânicos e matéria viva (microorganismos e plantas). Os componentes inorgânicos do solo representam mais de $90 \%$ da composição do mesmo. Estruturalmente, o solo pode ser dividido em três fases: sólida, líquida e gasosa.

A fase sólida é a matriz do solo e constitui-se dos componentes minerais e orgânicos. A fração mineral é constituída de partículas que variam de tamanho e composição. Podem ser agrupadas em três principais grupos de acordo com a granulometria: argila $(0-2 \mu \mathrm{m})$, silte $(2-63 \mu \mathrm{m})$ e areia (63-2000 $\mu \mathrm{m})$. A fração orgânica do solo contém vários tipos de partículas orgânicas. O húmus, parte da fração orgânica mais importante, é a matéria orgânica morta advinda de plantas e animais e consiste de um grande número de compostos diferentes que variam desde um simples ácido orgânico a um composto macromolecular complexo (Otten et al., 1997). Segundo Weiner (2000), a composição da parte húmica do solo é composta dos seguintes elementos: C (45-55\%), O (30-45\%), H (3-6\%), N (1-5\%) e S (0-1\%).

As fases aquosa e gasosa do solo são complementares entre si, pois ambas preenchem o volume dos poros. A composição da fase aquosa depende da idade e origem da água, dos constituintes da fase sólida e da presença ou ausência de microorganismos e raízes de plantas. Naturalmente, a fase gasosa só está presente na zona vadosa do solo. A composição do gás do solo é influenciada pelos processos físico-químicos e biológicos. Na presença de oxigênio os materiais reduzidos se oxidam. Os carbonatos e os minerais são dissolvidos, e o carbonato dissolvido pode escapar para a fase gasosa na forma de dióxido de carbono (Otten et al., 1997). 
Quando um contaminante atinge o solo por meio de vazamentos ele sofre a ação de fenômenos geoquímicos e biológicos e se distribuem em subsuperfície da seguinte forma, como mostra a Figura 4: fase vaporizada, fase residual ou adsorvida, fase livre e fase dissolvida. A distribuição do contaminante em tais fases dependerá de suas características físico-químicas e ainda do tipo de solo (Silva et al., 2004).

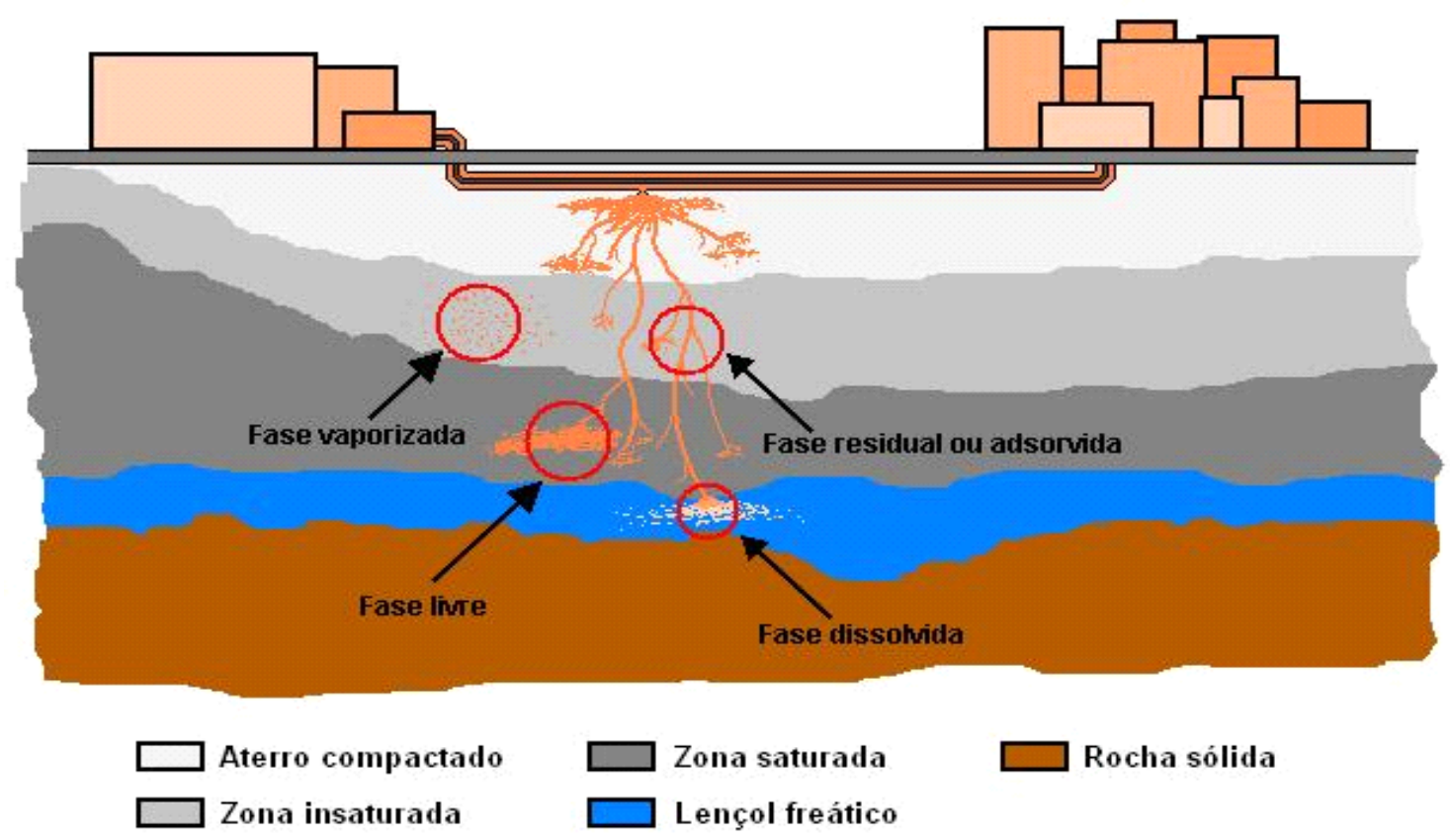

Figura 4: Comportamento de contaminante orgânico em subsolo (Costa et al., 1999)

Dentre os fatores que determinam a ligação dos contaminantes ao solo está a área superficial específica das partículas $\left(\mathrm{m}^{2} / \mathrm{g}\right)$ disponível. Além disso, as cargas elétricas das partículas da matriz do solo também influenciam na adsorção dos contaminantes ao meio. Vale ressaltar que quanto às propriedades físico-químicas, os contaminantes são classificados como DNAPL (dense non-aqueous phase liquid), quando a substância é mais densa que a água, e LNAPL (light non-aqueous phase liquid) quando é menos denso (Otten et al., 1997). O PCB é classificado como um DNAPL, ou seja, um contaminante orgânico de reduzida solubilidade e mais denso que a água e que, por isso, ao atingir o solo se apresenta como fase livre (Kueper et al., 2003). 


\subsubsection{Remediação de Solos}

Os processos geoquímicos e biológicos que determinam à mobilização e transformação dos compostos no meio poroso envolvem inúmeras variáveis, tornando o processo de remediação uma tarefa complexa. Portanto, para que a remediação seja satisfatória e atenda à legislação ambiental, faz-se necessário o conhecimento das tecnologias de tratamento disponíveis, suas limitações, relações custo-benefício, aplicabilidade quanto à hidrogeologia do sítio e da natureza do contaminante (Nobre e Nobre, 2003).

Várias são as técnicas existentes para o tratamento de solos contaminados por compostos orgânicos. As técnicas podem ser agrupadas conforme a transformação do contaminante em:

- Tecnologias de destruição;

- Tecnologias de separação física.

Ou ainda de acordo com o local onde ocorre o tratamento como:

- Técnicas ex situ, em que há a necessidade de escavação do local e posterior tratamento;

- Técnicas in situ, em que a remediação ocorre no local contaminado.

A depender da situação, a técnica escolhida pode ser usada tanto ex situ quanto in situ. Ambas têm vantagens e desvantagens. A principal vantagem do tratamento ex situ sobre o in situ é o tempo de remediação que é menor no primeiro tratamento. Já a vantagem do tratamento in situ sobre o ex situ é a economia do processo, pois em um caso de tratamento in situ os custos com transporte e remoção do solo contaminado são evitados (FRTR, 2007).

Existem inúmeros trabalhos que relatam o uso de diversas tecnologias de tratamento de solos contaminados por orgânicos. Algumas já aplicadas em escala comercial, outras ainda em fase de testes.

As tecnologias de destruição se baseiam principalmente no uso de altas temperaturas e métodos químicos. Dentre elas estão: a incineração, a redução química, a vitrificação in situ, oxidação química, fotólise, biorremediação, entre outras. As técnicas de separação física têm como objetivo reter ou isolar a área 
contaminada. Como exemplos dessas técnicas, tem-se: dessorção térmica, lavagem do solo, extração por solvente, extração supercrítica, etc (Almeida, 2005).

\subsubsection{Remediação de Solos Contaminados por PCBs}

No caso dos PCBs, a incineração ainda é o método mais utilizado até o presente momento para a destruição de solos contaminados por essas substâncias. O processo opera em temperaturas que variam entre $1.100^{\circ} \mathrm{C}$ e $1.300^{\circ} \mathrm{C}$ (Stow, 1997; Tooge, 2004). Este método, porém, apresenta certas inadequações pelo fato de ser relativamente caro, além de formar policloro dibenzodioxinas (PCDD) e policloro dibenzofuranos (PCDF) (Figura 5), compostos secundários muito mais tóxicos ao ambiente, devido à queima incompleta dos PCBs. A legislação mundial exige que a eficiência de destruição e remoção da incineração para esses compostos seja o mais próxima de 100\% para evitar a formação dos PCDDs/PCDFs (Kastánek e Kastánek, 2005). Esse motivo impulsionou o desenvolvimento de outras tecnologias mais limpas.

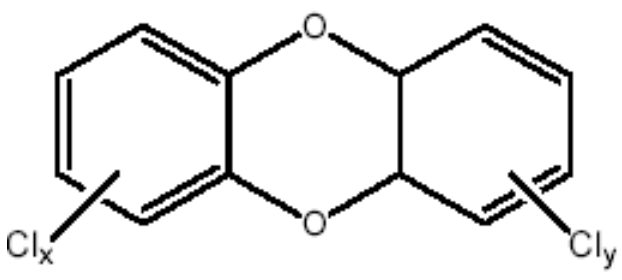

Policlorodibenzodioxina (PCDD)

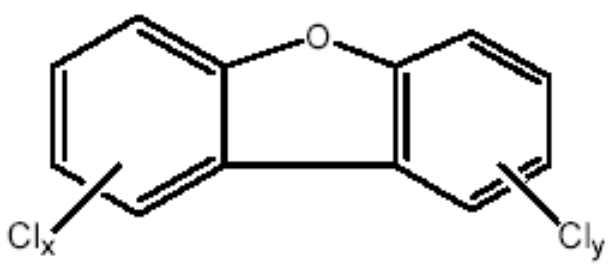

Policlorodibenzofurano (PCDF),

Figura 5: Estrutura molecular de uma dioxina e de um furano (Mesquita, 2004)

Outro método bastante estudado e aplicado para a remediação de solos contaminados por PCBs é a biorremediação que tanto pode ser via aeróbia quanto anaeróbia (Borja et al., 2005). A depender da extensão dos danos à área, os microrganismos utilizados podem ser os já existentes no meio. Otten (1997) explica que o curso da degradação através da biorremediação é guiado principalmente pelas condições do solo que são principalmente $\mathrm{o} \mathrm{pH}$, a disponibilidade de nutrientes, a presença de outros contaminantes e a temperatura. 
Uma técnica de separação de orgânicos em solos muito abordada é a extração por solventes orgânicos. Nesses casos, o contaminante orgânico é extraído do sítio contaminado e levado para um posterior tratamento de destruição como apresentado por Valentin (2000). Nesse trabalho foi realizada a extração in situ de PCBs de um solo utilizando alguns solventes. A remoção atingiu 99\% quando foram utilizados os solventes etil acetato e metil isobutil cetona.

A oxidação química tem se mostrado uma das técnicas promissoras para a remediação de solos contaminados por compostos orgânicos (Watts e Teel, 2006). Esta técnica se baseia na aplicação de fortes agentes oxidantes para degradar o orgânico. Ela tem sido aplicada tanto in situ quanto ex situ, mas tem ganhado popularidade como uma técnica in situ. E assim, a partir dos anos 90 surge uma nova classe de técnicas denominadas In Situ Chemical Oxidation (ISCO).

Assim como todos os outros processos, a ISCO também tem suas limitações que são principalmente: a reatividade do agente oxidante com o contaminante e a transferência de massa entre as fases adsorvida e aquosa que é onde normalmente ocorre a reação de oxidação (Watts, 1998).

Os agentes oxidantes mais utilizados em processos ISCO são o ozônio $\left(\mathrm{O}_{3}\right)$, o peróxido de hidrogênio $\left(\mathrm{H}_{2} \mathrm{O}_{2}\right)$ e o permanganato de potássio $\left(\mathrm{KMnO}_{4}\right)$. Cada um deles possui vantagens e desvantagens, e a aplicação depende do meio a ser tratado e do orgânico a ser degradado (EPA, 2005).

Dentre os agentes oxidantes utilizados numa remediação ISCO, a oxidação com o reagente de Fenton foi o primeiro processo estudado e desenvolvido em grande escala e continua sendo estudado por vários pesquisadores (Stow, 1997; Higarashi, 1999; Yeh et al., 2002; Mesquita, 2004).

Pesquisas recentes têm mostrado que os processos mais eficazes na destruição de poluentes orgânicos são os denominados de Processos Oxidativos Avançados (POAs). Os POAs são caracterizados pela geração de radicais hidroxila (HO•), que apresentam um alto potencial padrão de oxidação $\left(E_{0}=2,8 \mathrm{~V}\right)$, superior aos de outras espécies oxidantes, tais como $\mathrm{O}_{3}\left(\mathrm{E}_{0}=2,1 \mathrm{~V}\right), \mathrm{H}_{2} \mathrm{O}_{2}\left(\mathrm{E}_{0}=1,77 \mathrm{~V}\right)$ e $\mathrm{Cl}_{2}$ $\left(E_{0}=1,5 \mathrm{~V}\right)$ (Mattos et al., 2003). O sistema Fenton, um dos mais conhecidos processos oxidativos avançados, consiste na combinação de peróxido de hidrogênio e íons ferrosos formando radicais hidroxila (Equação 1). Os radicais hidroxila gerados então oxidam os compostos orgânicos do meio $(\mathrm{RH})$, conforme a Equação 
2, gerando intermediários que novamente são atacados por outros radicais hidroxila podendo chegar a completa mineralização $\left(\mathrm{CO}_{2}\right.$ e $\left.\mathrm{H}_{2} \mathrm{O}\right)$. Este sistema tem sido largamente estudado na oxidação de compostos orgânicos de alta toxicidade (Sedlak e Andren, 1994; Yeh et al., 2003; Wang e Lemley, 2006).

$\mathrm{Fe}^{2+}+\mathrm{H}_{2} \mathrm{O}_{2} \rightarrow \mathrm{Fe}^{3+}+\mathrm{OH}^{-}+\mathrm{HO}$
$\mathrm{HO} \cdot+\mathrm{RH} \rightarrow \cdots \rightarrow \mathrm{CO}_{2}+\mathrm{H}_{2} \mathrm{O}$

Os reagentes que compõem o sistema Fenton têm algumas vantagens que se sobressaem diante de outros: são compostos relativamente baratos e não-tóxicos, além da reação ocorrer em temperatura e pressão ambientes.

Sabe-se que o radical hidroxila oxida efetivamente compostos orgânicos em fase aquosa (Moraes, 2003), incluindo os PCBs (Stow, 1997). Porém, DNAPLs como os PCBs são muito insolúveis em água, devido a isso espera-se que a eficiência da oxidação química seja baixa e que ocorra através de um mecanismo indireto (o da dissolução do composto em fase aquosa), causando um acréscimo no tempo e no custo da remediação (Yeh et al., 2003). Acredita-se que a maioria dos compostos em fase adsorvida não pode ser oxidado diretamente porque os radicais hidroxila gerados são rapidamente consumidos na fase aquosa. Yeh et al. (2002) propôs que um dos mecanismos de degradação entre o oxidante, a matéria orgânica do solo e o contaminante adsorvido durante a oxidação por peróxido catalizada por ferro era "oxidação-dessorção-oxidação". Isso se deve ao fato de que a oxidação da matéria orgânica causada pelos radicais gerados libera o contaminante adsorvido para a fase aquosa que então é oxidado pelos radicais restantes.

A eficiência da oxidação química em solo é influenciada, principalmente, pelos seguintes fatores: tipo e concentração de ferro (Yeh et al., 2003), concentração de peróxido (Flotron et al., 2005), presença de outros compostos orgânicos competitivos pela hidroxila (Lindsey e Tarr, 2000) e pH (Wang e Lemley, 2006).

Por ser um problema de grande complexidade, para que a técnica de remediação de solo por oxidação química seja aplicada na prática, há que se fazer estudos iniciais em escala de laboratório para o completo entendimento da situação, e somente depois ser ampliada para escala comercial (Watts e Teel, 2006). 


\section{MATERIAIS E MÉTODOS}

Nesse trabalho foram realizados ensaios experimentais com o objetivo de entender melhor o comportamento do sistema solo-contaminante-oxidante. Com esse intuito, foram feitos ensaios para a caracterização do solo utilizado, extração do contaminante da matriz do solo e reações de oxidação usando o sistema Fenton para verificar a remoção do contaminante em estudo - as bifenilas policloradas.

\subsection{SOLO}

\subsubsection{Preparação do Solo}

O solo utilizado nos experimentos foi obtido através de uma sondagem a trado manual feita por uma empresa contratada pela Eletropaulo. A amostragem do solo foi feita na Rua Alvarenga em São Bernardo do Campo, Estado de São Paulo. No momento da sondagem, em campo, a amostra foi caracterizada quanto à cor e à textura.

Antes de ter sido usado em qualquer ensaio experimental, o solo foi macerado e passado em peneira de $2 \mathrm{~mm}$ (\#10 mesh) para que o mesmo ficasse homogêneo, ou seja, com uma granulometria uniforme (Wang e Lemley, 2006; Rissato et al., 2006).

\subsubsection{Caracterização do Solo}

\subsubsection{Medida do $\mathrm{pH}$}


$\mathrm{O} \mathrm{pH}$ do solo foi determinado utilizando-se um método baseado em Silva et al. (2006). O procedimento consistia em colocar $100 \mathrm{~mL}$ de água destilada sobre uma amostra de $10 \mathrm{~g}$ de solo. O solo ficou em contato com a água por 1 hora em repouso e, em seguida, usando papel de $\mathrm{pH}$ foi determinado o valor do $\mathrm{pH}$ do solo. Esse procedimento foi realizado para duas amostras de solo, ou seja, em duplicata.

\subsubsection{Teor de Umidade}

Esses experimentos tinham como objetivo determinar o teor de umidade do solo utilizado nos experimentos para que esse valor fosse descontado nos cálculos da degradação do contaminante no solo.

Inicialmente, em cadinhos de porcelana, 5 diferentes amostras de solo bruto (1 g) foram pesadas em balança analítica. Em seguida, essas amostras de solo foram colocadas numa estufa a $100^{\circ} \mathrm{C}$ por 1 hora. Após secagem na estufa, as amostras ficaram no dessecador até atingirem a temperatura ambiente, que era de aproximadamente $25^{\circ} \mathrm{C}$. Por último as amostras foram pesadas novamente. O teor de umidade foi então calculado por média simples da diferença gravimétrica. $O$ método foi baseado em Silva et al., 2006.

\subsubsection{Teor de Carbono Orgânico}

Para eliminar mais uma variável de erro no cálculo da degradação do PCB no solo, foi determinado o teor de carbono orgânico do solo. Para tal, semelhante ao procedimento anterior, 5 diferentes amostras de solo bruto $(1 \mathrm{~g})$ foram pesadas em cadinhos de porcelana em balança analítica. Em seguida, essas amostras de solo foram colocadas em um forno mufla a $1000^{\circ} \mathrm{C}$ por 1 hora. Após a calcinação na mufla, as amostras ficaram no dessecador até atingirem a temperatura ambiente, que era de aproximadamente $25^{\circ} \mathrm{C}$. Por fim, as amostras foram pesadas novamente. 
O teor de orgânicos foi calculado através de média simples da diferença gravimétrica.

\subsubsection{Teor de Carbono Inorgânico do Solo}

Esse ensaio tinha como objetivo determinar o teor de carbono inorgânico, os cabornatos, do solo utilizado nos experimentos para que esse valor fosse descontado nos cálculos da degradação do contaminante no solo.

Para isso, uma amostra de $10 \mathrm{~g}$ de solo no seu $\mathrm{pH}$ natural $(\mathrm{pH}=5,0)$ foi posta em contato com $100 \mathrm{ml}$ de água. O conjunto ficou sob agitação de $110 \mathrm{rpm}$ por 24 horas em um agitador orbital. Em seguida deixou-se a amostra em repouso para que a água sobrenadante fosse amostrada e analisada em TOC. O mesmo procedimento foi aplicado para uma amostra de solo com $\mathrm{pH}$ ácido igual a 3,0. O pH foi ajustado com ácido sulfúrico concentrado $\left(\mathrm{H}_{2} \mathrm{SO}_{4}, 1 \mathrm{M}\right)$. Para ambas as amostras não foi obtido resultado satisfatório, pois o equipamento não conseguiu detectar nenhuma substância.

\subsubsection{4 Área Superficial Específica}

O solo é um adsorvente natural e heterogêneo. Em função disso, um dos fenômenos que rege a disponibilidade do contaminante orgânico para um tratamento efetivo de degradação é a adsorção. Esse fenômeno pode ser representado através da área superficial específica que é uma característica textural do solo e indica a área disponível do solo para adsorção do contaminante. Inúmeros são os trabalhos que tentam modelar o fenômeno (Breus et al., 2006; Filimonova et al., 2006).

Usando um Quantachrome Autosorb Automated Gas Sorption System (Figura 6), o solo foi caracterizado através da isoterma de adsorção do nitrogênio gasoso $\left(\mathrm{N}_{2}\right)$ a $77 \mathrm{~K}$. A área superficial específica foi determinada automaticamente pelo 
equipamento que gera o valor pelo ajuste do modelo de Brunauer-Emmett-Teller (BET).

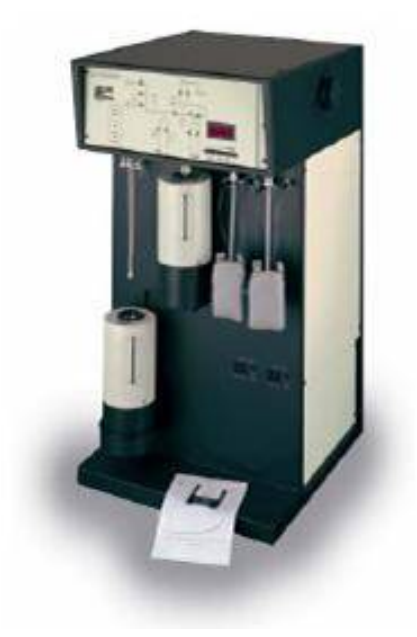

Figura 6: Equipamento Autosorb da Quantachrome para determinação de área superficial específica (BET)

O ensaio foi realizado pelo Grupo de Pesquisas em Separações por Adsorção (GPSA) localizado no Departamento de Engenharia Química da Universidade Federal do Ceará (UFC).

\subsection{DEGRADAÇÃO DAS BIFENILAS POLICLORADAS}

Nesse trabalho, propõe-se o uso da oxidação química com Reagente de Fenton para o tratamento de solos contaminados por PCBs. Esse método consiste em adicionar ao sistema uma quantidade desejada de peróxido de hidrogênio e sal de ferro para gerar radicais hidroxila, os quais irão degradar o contaminante orgânico.

O cálculo das quantidades dos reagentes oxidantes aplicados ao solo peróxido de hidrogênio $\left(\mathrm{H}_{2} \mathrm{O}_{2}, 30 \%\right)$ e sulfato de ferro heptahidratado $\left(\mathrm{FeSO}_{4} .7 \mathrm{H}_{2} \mathrm{O}\right)$ - foi baseado no monoclorobifenil $\left(\mathrm{C}_{12} \mathrm{H}_{9} \mathrm{Cl}\right)$ de massa molecular $188,7 \mathrm{~g} / \mathrm{mol}$, pois estequiometricamente ele é o congênere de PCB que exige maior quantidade de 
reagentes oxidantes. Portanto, foi considerado que todo o ascarel utilizado era composto exclusivamente de monoclorobifenil.

Para eliminar o máximo possível de interferências externas e melhorar os resultados, a metodologia experimental foi sendo ajustada ao longo do trabalho. $\mathrm{O}$ procedimento experimental consistia basicamente de três etapas: etapa de contaminação do solo, etapa da reação de oxidação Fenton e por fim, a etapa da quantificação dos resultados (extração Soxhlet e análise em Cromatografia Gasosa acoplada a Espectrômetro de Massa (CG/MS)). Tais etapas estão detalhadas a seguir.

\subsubsection{Contaminação Simulada do Solo}

O procedimento de contaminação simulada do solo foi determinado através de um apanhado de trabalhos de outros autores como Riaza-Frutos et al. (2007), Wang e Lemley (2006) e Bogan e Trbovic (2003).

Inicialmente, uma amostra de solo limpo (20 g) foi pesada em um béquer de $100 \mathrm{~mL}$. Em um balão volumétrico de $100 \mathrm{~mL}$ pesou-se 0,12 g de ascarel (amostra comercial de PCBs), aproximadamente, e completou-se o volume com n-hexano (VETEC, 99\% P.A.). Devidamente homogeneizada, esta solução foi adicionada ao solo contido no béquer, agitada em um agitador orbital (Kline Sppencer Scientific modelo 109-1TC) por 2 horas e deixada em repouso até que todo o solvente (nhexano) evaporasse a temperatura e pressão ambientes. Tinha-se, portanto, um solo contaminado com uma quantidade conhecida de ascarel, com concentração inicial em torno de $6000 \mathrm{mg}$ de ascarel/kg de solo, ou seja, 6000 ppm.

\subsubsection{Oxidação com o Reagente de Fenton}

A etapa de oxidação dos contaminantes em solo foi definida a partir das condições disponíveis em escala de laboratório, tomando como referência outros 
trabalhos (Watts et al., 2000). O sistema reacional operou em batelada com uma única aplicação dos reagentes, cujas concentrações variaram de acordo com as condições experimentais impostas.

O solo contaminado foi dividido em alíquotas de $3 \mathrm{~g}$ e colocados em frascos de cor âmbar de $125 \mathrm{~mL}$ (Figura 7). A cada frasco, $10 \mathrm{ml}$ de água destilada era adicionada, formando uma pasta. E só depois era adicionado o reagente de Fenton, $\mathrm{H}_{2} \mathrm{O}_{2}(30 \%)$ e $\mathrm{FeSO}_{4} .7 \mathrm{H}_{2} \mathrm{O}$, na quantidade desejada. Os frascos fechados ficaram sob agitação em agitador orbital por um período de tempo pré-determinado (tempo de reação). Em cada experimento também foi realizado um ensaio denominado "branco" (B), com a parcela do solo contaminado com ascarel que não possuía o agente oxidante.

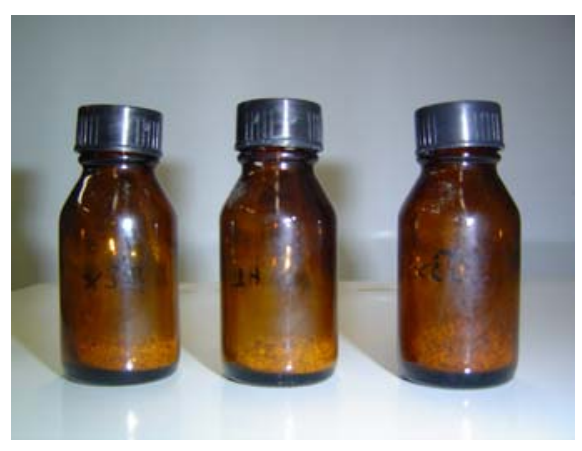

Figura 7: Células de reação

\subsubsection{Extração do Contaminante}

Com o término da reação, as amostras de solo foram filtradas, por filtração simples. Em seguida, foram deixadas a temperatura ambiente por 24 horas, aproximadamente, até que a umidade evaporasse o máximo possível.

Após a filtração, as extrações foram realizadas em extrator Soxhlet automático. No início foram realizadas no extrator da TECNAL modelo Te-044-8/50 (Figura 8). As últimas extrações foram executadas em um outro extrator também automático da Gerhardt modelo Soxtherm Multistat / SX PC (Figura 9).

A primeira etapa consistia em adicionar às cubetas de extração $100 \mathrm{~mL}$ de um determinado solvente. Na maioria dos experimentos foi utilizado n-hexano como 
solvente. Mas outros ensaios foram feitos usando álcool etílico e n-hexano/acetona (1:1) como solvente de extração. Após dosado o solvente, as amostras de solo eram colocadas no equipamento dentro de cartuchos de celulose. O sistema era então programado para operar na temperatura desejada, a depender do solvente utilizado, sendo finalmente iniciado o processo de extração. Após 7 horas de extração, o extrato era padronizado para $100 \mathrm{~mL}$. Por fim, era retirada uma alíquota de $1 \mathrm{~mL}$ desse extrato, agora contendo os poluentes extraídos, e colocada em frascos apropriados (vials), mostrados na Figura 10, para ser analisada via CG/MS.

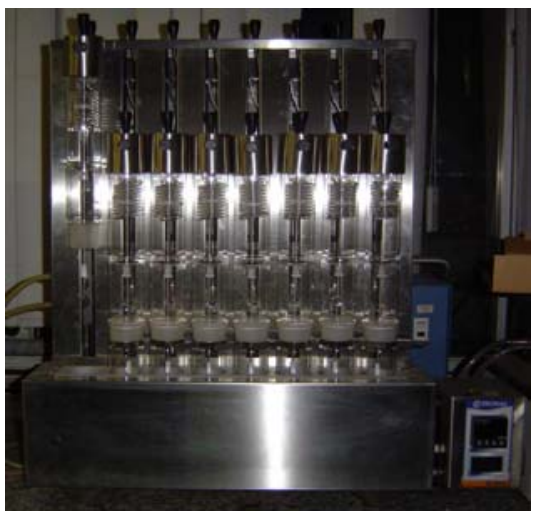

Figura 8: Extrator Soxhlet da TECNAL

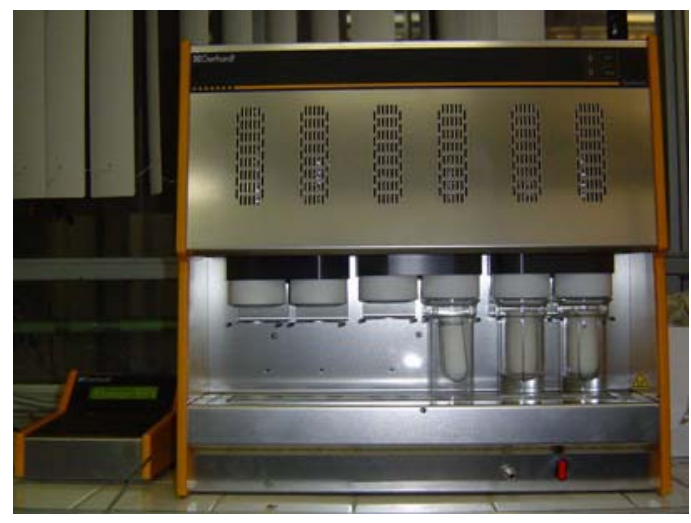

Figura 9: Extrator Soxhlet da Gerhardt

Além de fazer parte da etapa analítica do processo de obtenção dos resultados da degradação através da oxidação química, a extração também pode ser utilizada como uma técnica de remoção de contaminantes orgânicos de solos e sedimentos, sendo muitas vezes utilizada como uma primeira fase do processo de remediação de áreas contaminadas (Valentin, 2000).

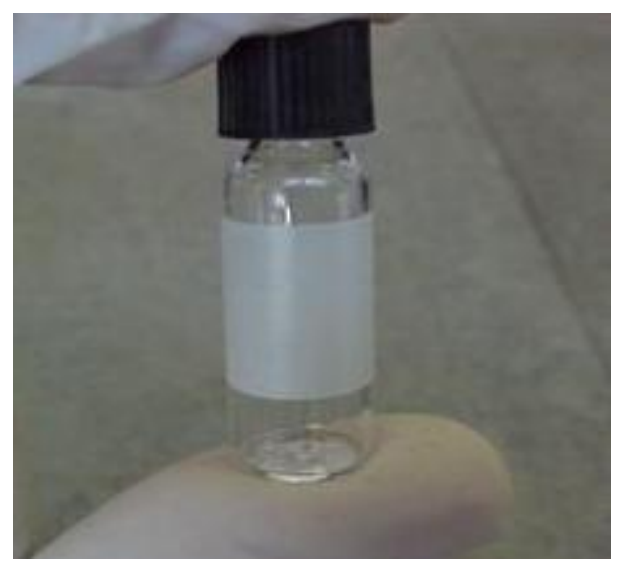

Figura 10: Vial para análise cromatográfica do extrato 


\subsubsection{Cromatografia Gasosa / Espectrômetro de Massa (CG/MS)}

O extrato, contendo os possíveis orgânicos não degradados pela reação, foi analisado qualitativamente usando a técnica de cromatografia gasosa acoplada a espectrômetro de massa (CG/MS). As análises de CG/MS foram realizadas em um cromatógrafo GC-17A da Shimadzu (Figura 11). O espectrômetro operou com ionização por impacto eletrônico de 70 eV e varredura de 10 a 9200 u.m.a.. As bases de dados usadas para comparação de espectros de massa foram as da NIST (National Institute of Standards and Technology) de 1990, com 60.000 espectros. Foi utilizada uma coluna capilar do tipo VF-1301MS (30 m x 0,25 mm x 0,25 $\mu \mathrm{m}$; 6\%cyanopropylphenyll 94\%- methylpolysiloxano).

As condições do método de análise cromatográfica, adaptadas de Shu et al. (1994), foram:

- Volume injetado: $1 \mu \mathrm{L}$;

- Fluxo na coluna: 0,7 mL/min;

- Temperatura do Injetor: $280^{\circ} \mathrm{C}$;

- Programação de temperatura da coluna: $60^{\circ} \mathrm{C}(3 \mathrm{~min}) / 60-250^{\circ} \mathrm{C}\left(10^{\circ} \mathrm{C} / \mathrm{min}\right.$ por $15 \mathrm{~min}) / 250-300^{\circ} \mathrm{C}\left(5^{\circ} \mathrm{C} / \mathrm{min}\right.$ por $\left.10 \mathrm{~min}\right)$;

- Gás de arraste: hélio.

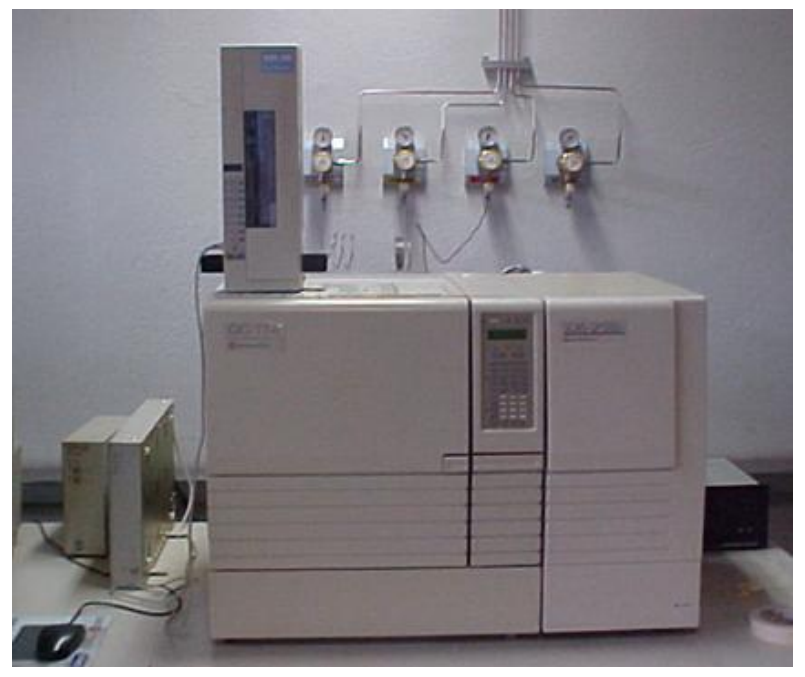

Figura 11: Cromatógrafo da Shimadzu utilizado nas análises das amostras 
O método utilizado não é o mais indicado pela literatura, que recomenda o uso de CG acoplado a um detector de captura de elétrons (ECD) (USEPA,2000), específico para compostos organoclorados.

As análises cromatográficas realizadas nas amostras de PCBs geram cromatogramas semelhantes ao da Figura 12. É composto basicamente de três tipos de congêneres de PCBs e seus isômeros: pentaclorobifenilas, hexaclorobifenilas e heptaclorobifenilas. O tempo de retenção dos picos ocorre normalmente entre 20 e 40 minutos.

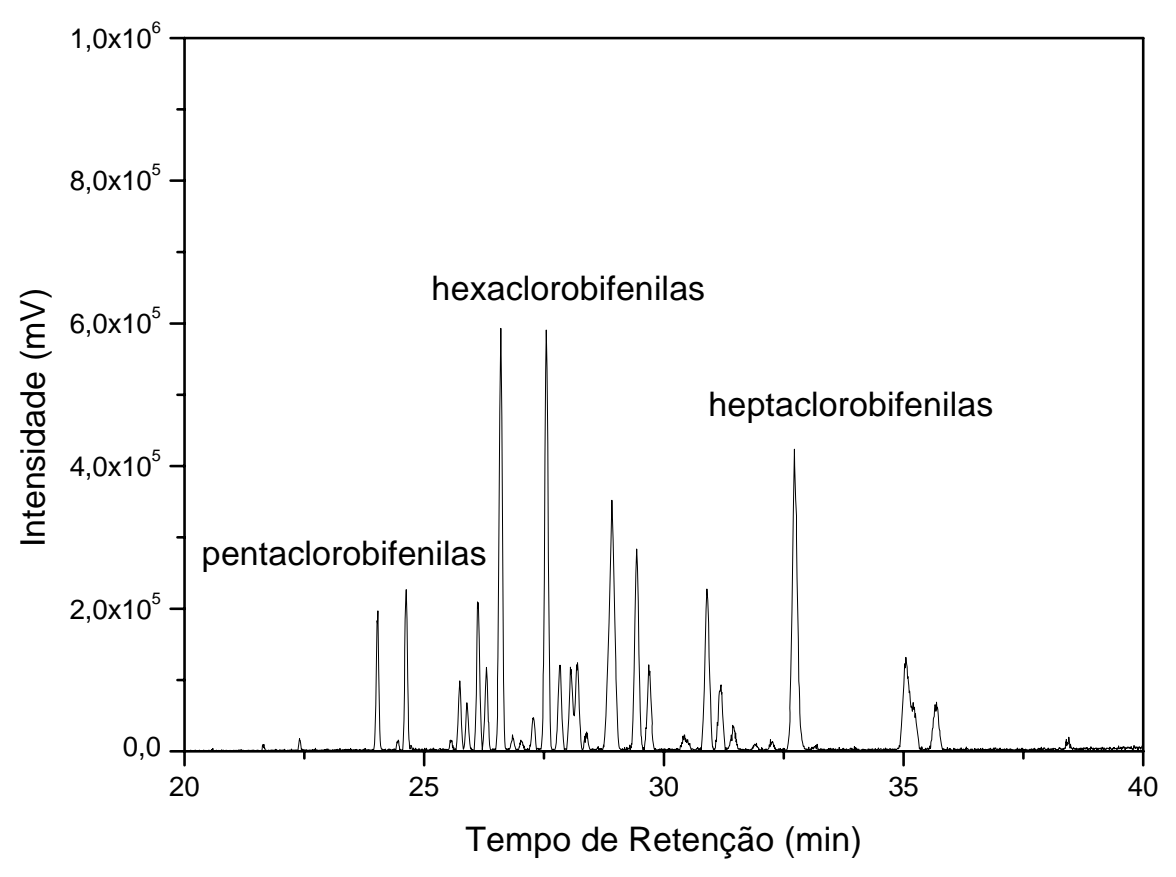

Figura 12: Cromatograma típico dos PCBs 


\section{RESULTADOS E DISCUSSÃO}

Os resultados dos ensaios foram divididos em três grupos:

1. Ensaios de caracterização do solo utilizado nos experimentos;

2. Ensaios da etapa de extração do contaminante do solo;

3. E ensaios de oxidação do contaminante na matriz do solo.

Cada um deles está detalhado nos itens que se seguem.

\subsection{CARACTERIZAÇÃO DO SOLO}

O solo estudado tem sua origem em São Bernardo do Campo, Estado de São Paulo, e foi amostrado de uma profundidade de 1,80 - 2,15 m. Quanto à cor, foi caracterizado em campo como amarelo claro, como pode ser visto na Figura 13, pela empresa que realizou a sondagem. Essa característica nos faz inferir que se trata de um solo que possui pequena quantidade de óxidos de ferro e compostos húmicos, pois essas substâncias são fundamentais na determinação da cor escura de um solo (Weiner, 2000).

Os outros dados de caracterização do solo estão detalhados a seguir.

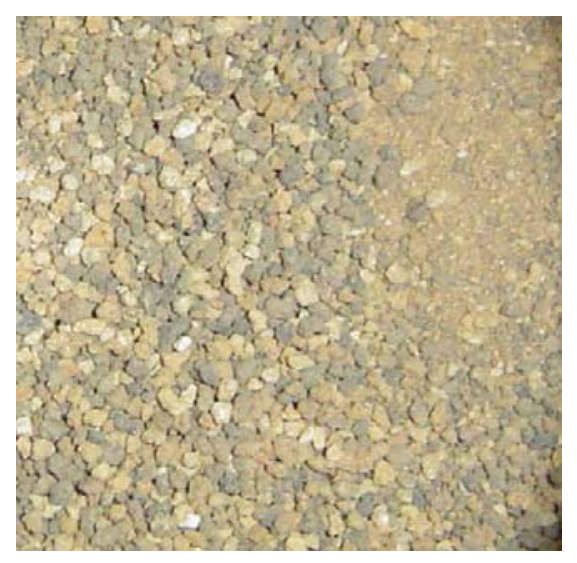

Figura13: Amostra de solo utilizado nos experimentos 


\subsubsection{Determinação do pH do Solo}

A determinação do $\mathrm{pH}$ do solo é importante pois esse parâmetro é de fundamental importância quando se está trabalhando com o reagente de Fenton, pois o mesmo é muito sensível ao pH do meio reacional (Yeh et al., 2002). Um pH ácido normalmente favorece a oxidação através do sistema Fenton, porém a acidez em solo pode causar impactos ecológicos dramáticos (Flotron et al., 2005).

Yeh et al. (2002) trabalharam com sistemas semelhantes sem alterar o pH do meio e obtiveram remoções com resultados em torno de 90\% para solos contaminados com clorofenóis, que são valores satisfatórios na remoção de poluentes orgânicos. Watts et al. (1994) mostraram que com a redução do pH do meio reacional obtém-se também resultados da ordem de 90\%.

Usando o procedimento do item 4.1.2.1, verificou-se que o pH do solo estudado era levemente ácido e igual a 5,0 em ambas as amostras. Esse fato é coerente pois o pH ácido promove com maior eficiência a oxidação usando o sistema Fenton, já que em meio básico os íons ferrosos tendem a precipitar e assim impedem a ocorrência da reação (Kuo, 1992). Portanto, nos ensaios realizados optou-se por não alterar o pH natural do meio.

\subsubsection{Umidade do Solo}

De acordo com o procedimento experimental descrito no item 4.1.2.2, as amostras foram secadas em estufa por 1 hora a uma temperatura de $105^{\circ} \mathrm{C}$. Foram utilizadas 5 amostras para o cálculo da umidade através de média simples. Os dados referentes aos cálculos estão mostrados na Tabela 4. Pelas análises, o solo possui $0,016 \mathrm{~g}$ de $\mathrm{H}_{2} \mathrm{O} / \mathrm{g}$ solo, ou seja, 1,628\% de umidade. 
Tabela 4: Dados referentes ao cálculo da umidade do solo

\begin{tabular}{ccccc}
\hline Amostras & Solo Bruto (g) & Solo Seco (g) & Umidade (g) & Umidade (\%) \\
\hline $\mathbf{1}$ & 1,025 & 1,005 & 0,020 & 1,951 \\
$\mathbf{2}$ & 1,082 & 1,066 & 0,016 & 1,479 \\
$\mathbf{3}$ & 1,007 & 0,992 & 0,015 & 1,490 \\
$\mathbf{5}$ & 1,016 & 0,999 & 0,017 & 1,673 \\
\hline Média & 1,030 & 1,014 & 0,016 & 1,553 \\
\hline
\end{tabular}

\subsubsection{Determinação do Teor de Orgânicos do Solo}

A quantidade de substâncias orgânicas originalmente presentes no solo bruto é uma característica bastante relevante, pois elas podem competir com o contaminante pelo reagente oxidante, e assim diminuir a eficiência do processo de oxidação química. Sedlak e Andren (1994) e Flotron et al. (2005) relataram a importância da quantidade de matéria orgânica do solo em processos de descontaminação química.

Na determinação de compostos orgânicos do solo, procedeu-se similarmente ao método de Stow (1997). Uma amostra de $1 \mathrm{~g}$ de solo foi calcinada a $1000^{\circ} \mathrm{C}$ em forno mufla, para garantir que todos os compostos orgânicos fossem calcinados. Os dados podem ser vistos na Tabela 5.

Portanto, o solo possui 9,944 \% de orgânicos e água. Subtraindo o valor da umidade determinado no item 5.1.2 que é de 1,628 \%, o teor de orgânicos do solo é de, aproximadamente, 8,316\%, que é um valor típico. Bogan e Trbovic (2003) usaram seis tipos diferentes de solos em seus experimentos de degradação de hidrocabonetos poliaromáticos (PAHs) que possuíam teor de carbono orgânico (TOC) variando, aproximadamente, entre $3 \%$ e $24 \%$. 
Tabela 5: Dados referentes ao cálculo do teor de orgânicos do solo

\begin{tabular}{ccccc}
\hline Amostras & Solo Bruto (g) & Solo Seco (g) & Orgânicos (g) & Orgânicos (\%) \\
\hline $\mathbf{1}$ & 1,025 & 0,918 & 0,107 & 10,478 \\
$\mathbf{2}$ & 1,082 & 0,979 & 0,103 & 9,556 \\
$\mathbf{3}$ & 1,007 & 0,911 & 0,096 & 9,533 \\
$\mathbf{4}$ & 1,016 & 0,914 & 0,102 & 10,000 \\
$\mathbf{5}$ & 1,030 & 0,925 & 0,105 & 10,165 \\
\hline Média & 1,032 & 0,929 & 0,103 & 9,944 \\
\hline
\end{tabular}

\subsubsection{Granulometria do Solo}

A caracterização granulométrica do solo foi determinada por Rodriguez (2006) que utilizou o mesmo solo em seus experimentos. A granulometria foi obtida através do método quantitativo da pipeta de Robinson, no laboratório de Geoquímica no Instituto de Ciências da USP. Essa propriedade textural é importante pois infere sobre outras propriedades do solo como a porosidade, permeabilidade e capacidade de adsorção de contaminantes (Otten et al., 1997).

A granulometria determinada foi a seguinte: 39,93\% de argila, 9,01\% de silte e 49,22\% de areia. Portanto, segundo a granulometria obtida, o solo utilizado é um solo arenoso, pois possui maior fração de areia.

\subsection{5 Área Superficial Específica}

A adsorção dos contaminantes orgânicos à matriz do solo está ligada diretamente à área superficial específica das partículas $\left(\mathrm{m}^{2} / \mathrm{g}\right)$. Esta área superficial específica decresce sensivelmente com o aumento do diâmetro das partículas. Portanto, a capacidade de adsorção de partículas arenosas é negligenciável se 
comparada à frações minerais menores como as argilas ou frações orgânicas (Otten et al., 1997).

Os dados das características texturais determinadas pela isoterma de adsorção de nitrogênio a $77 \mathrm{~K}$ utilizando o modelo de BET encontram-se na Tabela 6.

Tabela 6: Características texturais do solo

\begin{tabular}{cc}
\hline Característica Textural & Valor \\
\hline Área Superficial Específica & $24,52 \mathrm{~m}^{2} / \mathrm{g}$ \\
Volume de Poros & $0,1398 \mathrm{~cm}^{3} / \mathrm{g}$ \\
Diâmetro Médio de Partícula & $228,1 \AA$ \\
\hline
\end{tabular}

Os valores das características texturais do solo apresentados na Tabela 6 encontram-se em concordância com um solo de características semelhantes utilizado no trabalho de Bogan e Trbovic (2003), cujo valor de área superficial específica é de $24,49 \mathrm{~m}^{2} / \mathrm{g}$ de solo.

\subsection{EXTRAÇÃO SOXHLET}

Tradicionalmente, a extração do tipo Soxhlet tem sido o método mais utilizado na extração de PCBs da matriz de solos e sedimentos (Sporring et al., 2005). É o método 3541 de 1994 sistematizado e recomendado pela Environmental Protection Agency (EPA).

A etapa de extração na metodologia proposta para tratamento do solo contaminado com PCB é de fundamental importância, pois se a mesma não for eficiente não é possível quantificar fielmente a degradação ocorrida.

A extração é uma etapa complexa no processo estudado. A eficiência da extração utilizada para a determinação dos PCBs depende de vários fatores que são: método de extração (Sporring et al., 2005), tempo de extração (Valentin, 2000), tipo de solvente (Jakher, 2007) e composição da matriz (Bandh et al., 2000).

Portanto, para adaptar o sistema estudado a fim de se obter resultados satisfatórios foram realizados testes de extração para determinar o melhor tempo de 
extração e o melhor solvente entre n-hexano, n-hexano/acetona (1:1, v/v) e álcool etílico.

\subsubsection{Tempo de Extração}

Esses experimentos tinham como objetivo estudar a influência do tempo na extração, etapa imprescindível para as análises em CG/MS. Com esses resultados, desejava-se determinar um tempo ótimo de extração, ou seja, o tempo mínimo para obter uma quantidade máxima de poluentes orgânicos extraídos.

Para esse fim, uma massa de solo foi pesada e dividida em duas partes iguais, sendo uma delas contaminada com uma quantidade conhecida de óleo ascarel. Dessa parcela contaminada, foram retiradas as amostras para extração.

As extrações foram realizadas em um extrator automático da TECNAL modelo Te-044-8/50. A primeira etapa consistia em pesar as "cubetas de extração", às quais foram adicionados $100 \mathrm{~mL}$ de $\mathrm{n}$-hexano, que foi utilizado como solvente. Cerca de 2 $\mathrm{g}$ do solo contaminado foram então pesadas e colocadas em cartuchos de celulose, sendo finalmente iniciado o processo de extração. Após o final do tempo de extração, as cubetas foram pesadas. Uma amostra do solvente, agora contendo os poluentes extraídos, era então retirada e analisada via cromatografia gasosa. A extração foi conduzida de forma que somente o vapor de n-hexano circulava através da amostra de solo, variando-se o tempo de extração (1, 2, 3 e 4 horas). Também foi realizado um experimento de extração, denominado "branco" (B), com a parcela do solo que não foi contaminada com óleo ascarel, usando também uma massa de $2 \mathrm{~g}$. Os resultados do experimento encontram-se na Tabela 7. 
Tabela 7: Dados experimentais do ensaio de tempo de extração

\begin{tabular}{cccccc}
\hline Amostras & $\begin{array}{c}\mathbf{m}_{\text {cubeta }}(\mathbf{g}) \\
\text { pré-ext }\end{array}$ & $\begin{array}{c}\mathbf{m}_{\text {cubeta }}(\mathbf{g}) \\
\text { pós-ext }\end{array}$ & $\mathbf{m}_{\text {solo }}(\mathbf{g})$ & $\mathbf{m}_{\text {extrato }}(\mathbf{g})$ & $\begin{array}{c}\text { Tempo de } \\
\text { Extração (h) }\end{array}$ \\
\hline 1 & 130,9495 & 130,9514 & 2,0498 & 0,0019 & 1 \\
2 & 137,8176 & 130,8202 & 2,0148 & 0,0026 & 2 \\
3 & 130,2720 & 130,2777 & 2,0146 & 0,0057 & 3 \\
4 & 133,4570 & 133,4586 & 2,0057 & 0,0016 & 4 \\
B & 131,5640 & 131,5635 & 2,0274 & 0,0000 & 4 \\
\hline
\end{tabular}

A massa teórica de óleo ascarel, presente em $2 \mathrm{~g}$ do solo contaminado, corresponde a 0,018 g. Entretanto, pela Tabela 7, pode-se perceber que a extração realizada exclusivamente com o vapor do n-hexano circulando através da amostra não foi satisfatória, pois as massas de contaminante obtidas ao fim da extração foram bem inferiores ao valor teórico.

Nesse contexto, o procedimento para a extração foi então modificado, sendo as amostras de solo imersas no solvente, facilitando a migração dos contaminantes da fase sólida para o solvente. Foram realizados experimentos com os seguintes tempos de duração: 1, 2, 3 e 4 horas. Para avaliar o desempenho do processo de extração foram escolhidos três congêneres de PCBs, sendo um pentaclorobifenila, um hexaclorobifenila e um heptaclorobifenila, caracterizados pelos respectivos tempos de retenção: 24,5, 27,5 e 32,5 minutos. Observando-se as áreas dos picos na Figura 14 dos referidos congêneres de PCBs obtidos dos cromatogramas dos extratos das amostras, pode-se concluir que entre 3 e 4 horas as áreas dos congêneres de PCBs apresentaram os valores máximos e tendem à constância. Diante dessa observação, optou-se por realizar todas as extrações seguintes com um tempo de 7 horas de operação, garantindo que seria extraído o máximo possível de orgânicos.

Dependendo das variáveis do sistema de extração como tipo de contaminante, umidade do solo e tipo de solvente, o tempo de extração pode durar poucas ou muitas horas. Por exemplo, Sporring et al. (2005) obtiveram resultados próximos de $100 \%$ de recuperação de PCBs em solo usando n-hexano/acetona (1:1, v/v) em 18 horas de extração Soxhlet. 


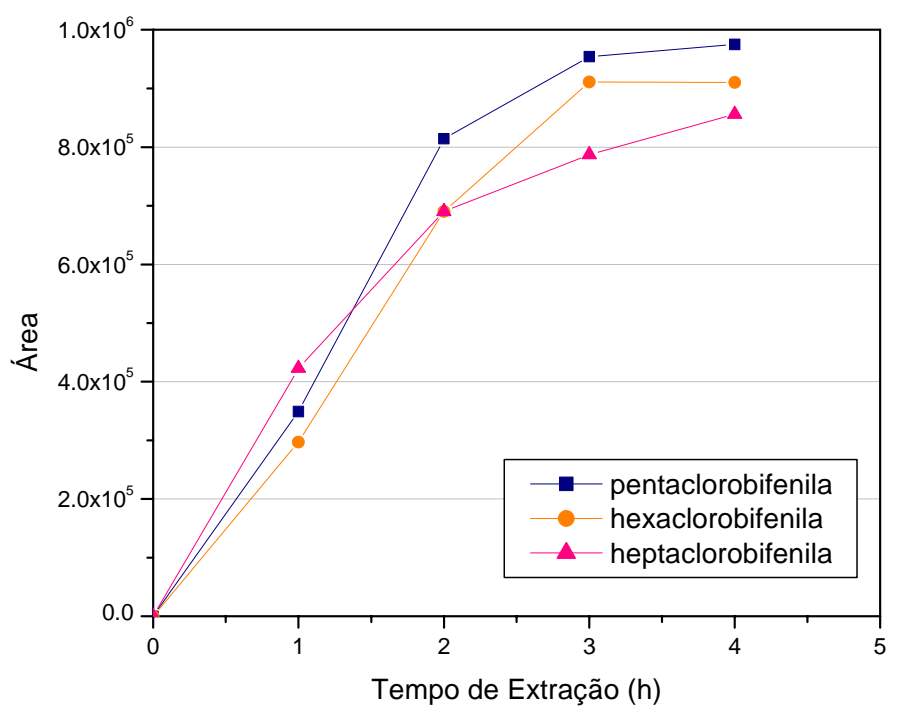

Figura 14: Extração dos congêneres de PCBs (pentaclorobifenila, hexaclorobifenila e heptaclorobifenila) ao longo do tempo de extração

\subsubsection{Influência da Umidade na Extração}

A reação de oxidação Fenton é extremamente facilitada em meio aquoso, pois promove a dessorção do contaminante favorecendo o ataque dos radicais hidroxila. Por essa razão recomenda-se que se adicione água ao sistema de reação formando uma lama (Villa e Nogueira, 2006). Porém, a umidade residual após o fim da reação aparece como uma barreira para a etapa de extração.

Em experimentos realizados inicialmente, suspeitava-se que a água utilizada nos experimentos em batelada poderia interferir na extração, impedindo que o contaminante fosse extraído ao máximo. Para confirmar tal hipótese foram feitos ensaios com o mesmo procedimento das extrações anteriores, porém com a adição de água ao solo contaminado formando uma pasta, seguida de filtração das amostras e só depois a extração com n-hexano. Os resultados obtidos para duas das amostras podem ser vistos nas Figuras 15 e 16.

Pode-se observar que as áreas dos picos de cada congênere de PCB para o experimento em meio aquoso (solo úmido) foram menores que as do experimento em ausência de água (solo seco). 


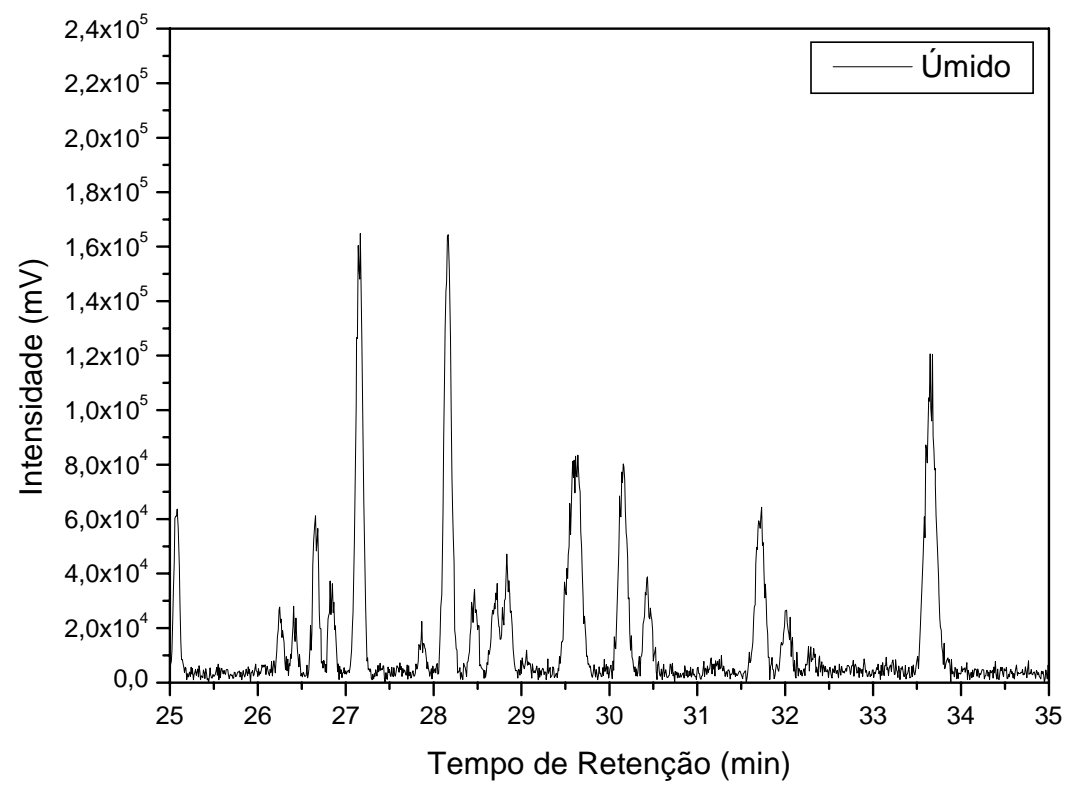

Figura 15: Intensidade dos picos de PCBs na extração em solo úmido

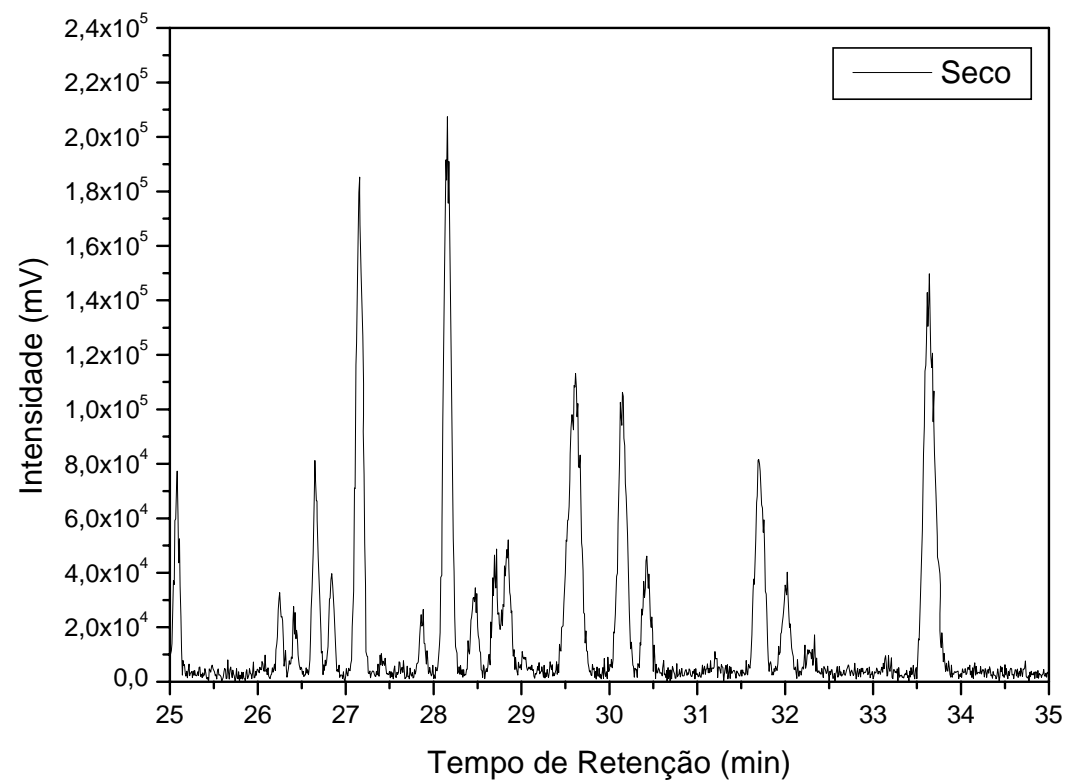

Figura 16: Intensidade dos picos de PCBs na extração em solo seco

Stow (1997) realizou um balanço de massa referente à reação de Fenton para a degradação de PCBs e concluiu que a extração dos contaminantes usando o sistema Soxhlet é ineficiente para solos com umidade residual, pois a água pode inibir o contato entre o solvente orgânico e o poluente. No caso apresentado pelas 
Figuras 15 e 16, o fenômeno é justificado pois a água e o n-hexano são substâncias imiscíveis.

\subsubsection{Teste de Solventes de Extração}

Tão importante quanto o tempo de extração é a escolha do solvente. Para melhorar a eficiência da extração dos PCBs do solo decidiu-se por testar outros solventes. Apesar de a literatura indicar o n-hexano como o solvente mais utilizado nos processos de extração de materiais contaminados com PCBs, foram realizados alguns ensaios experimentais utilizando, além do n-hexano, outros solventes: nhexano/acetona (1:1, v/v) e álcool etílico.

Os experimentos foram realizados em um extrator automático, modelo Soxtherm Multistat da Gerhardt, com os parâmetros de operação listados na Tabela 8.

Tabela 8: Parâmetros adotados para a extração dos PCBs em solo para três diferentes solventes

\begin{tabular}{ccc}
\hline Tipo de Solvente & Vol Solvente $(\mathrm{mL})$ & Temp Extração $\left({ }^{\circ} \mathrm{C}\right)$ \\
\hline n-hexano & 100 & 180 \\
n-hexano/acetona & $50 / 50$ & 180 \\
álcool etílico & 100 & 180 \\
\hline
\end{tabular}

Para os três solventes, foram feitos experimentos com dois tipos de amostras: solo contaminado seco e solo contaminado úmido. Para o solo contaminado úmido o melhor resultado obtido, considerando-se os mesmos três congêneres de PCBs do item 5.2.1, foi utilizando o etanol como solvente, que pode ser observado no gráfico da Figura 17. 


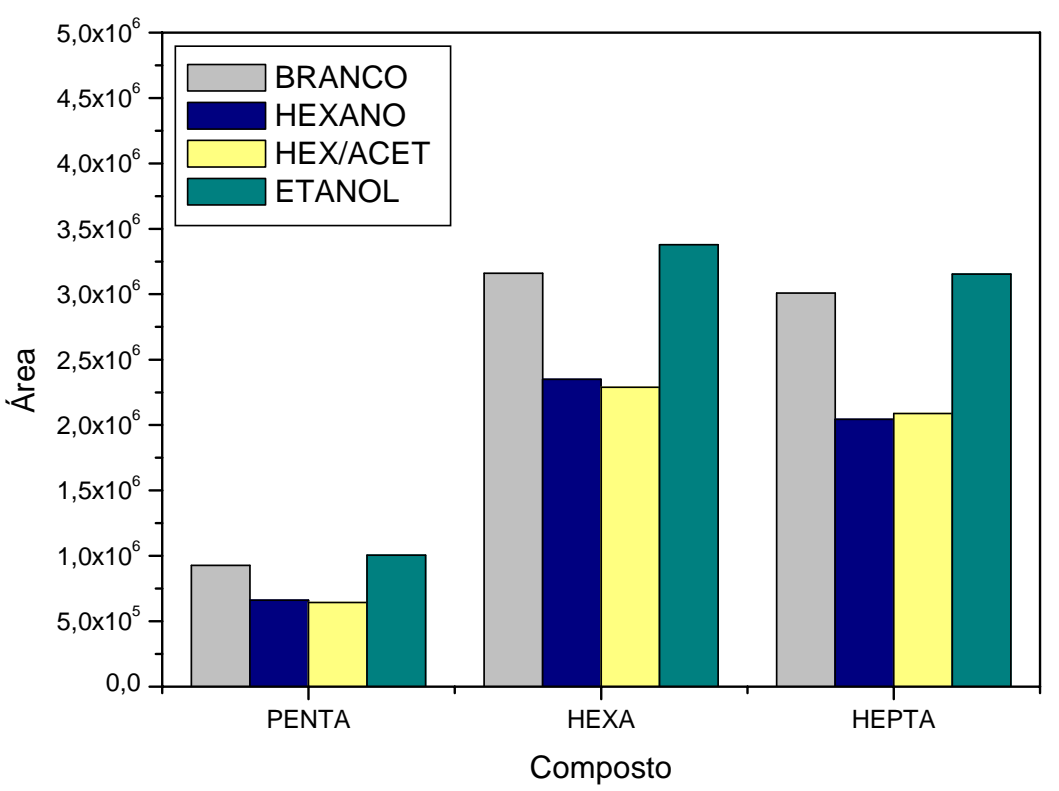

Figura 17: Áreas dos picos para os congêneres penta, hexa e heptaclorobifenila resultantes da extração da amostra úmida com diferentes solventes - hexano, hexano/acetona e etanol

A literatura (USEPA, 1994) normalmente recomenda a utilização da mistura de solventes hexano e acetona na proporção 1:1 para a extração do tipo Soxhlet de PCBs de solos e sedimentos. Pela Figura 17 vimos que a diferença na intensidade da área dos picos para os três congêneres foi praticamente igual para ambos os solventes (hexano e hexano/acetona).

Para as amostras de solo contaminado seco o comportamento dos solventes foi semelhante ao das amostras úmidas, evidenciando o etanol como melhor solvente de extração. Essa observação pode ser vista analisando-se o gráfico da Figura 18.

O fato de o álcool etílico ter se apresentado melhor que os outros dois solventes é inovador, pois em nenhuma das bibliografias consultadas recomendavase o uso do mesmo para executar extração de PCBs de amostras de solo. Isso se torna interessante pois, comparado aos outros dois solventes, o etanol é um solvente mais barato e menos tóxico. 


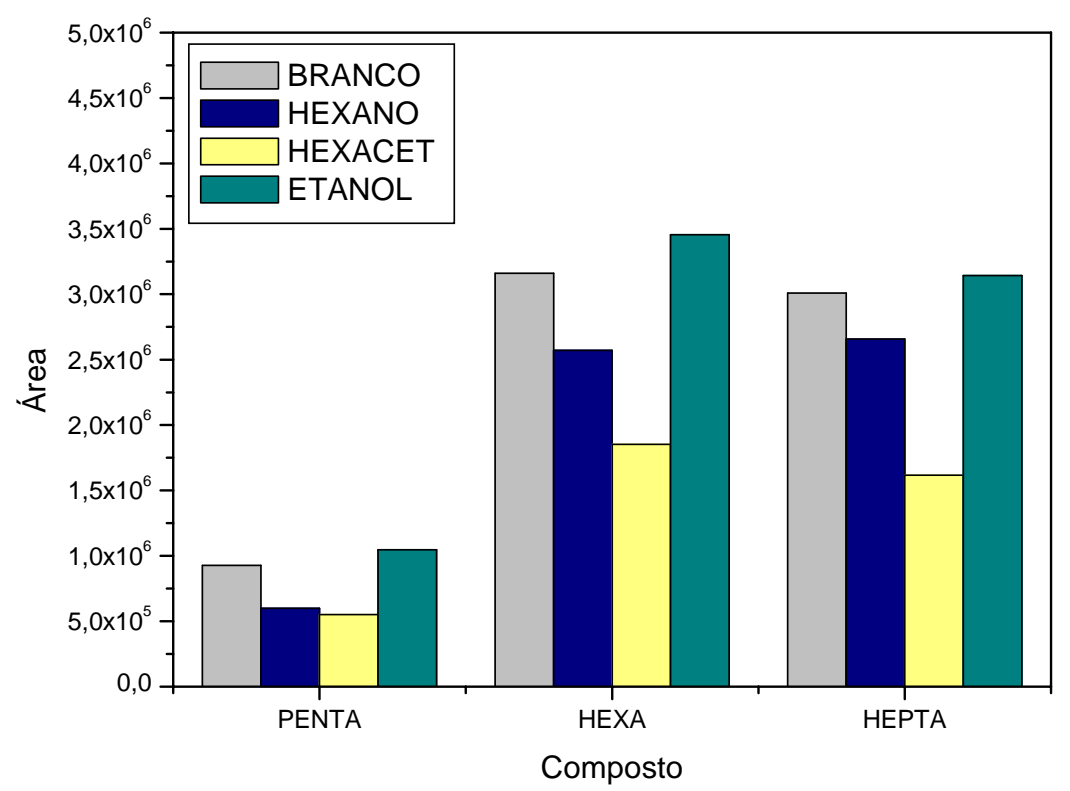

Figura 18: Áreas dos picos para os congêneres penta, hexa e heptaclorobifenila resultantes da extração da amostra seca com diferentes solventes - hexano, hexano/acetona e etanol

Comparando ainda as amostras seca e úmida para um mesmo solvente, foi visto que a umidade não foi um fator tão limitante na extração como ocorria com o equipamento da TECNAL, mostrando que o equipamento da Gerhardt possui um sistema de extração mais eficiente. A Figura 19 mostra os valores das áreas dos picos de hexaclorobifenila e heptaclorobifenila nas amostras de solo seco e úmido para os três solventes utilizados. Observamos ainda que para o solvente hexano/acetona, a amostra úmida apresentou intensidade de pico maior para ambos os congêneres. Isso pode ser explicado pela polaridade da mistura de solventes que é maior dos que a dos outros dois solventes. Para os outros dois solventes, hexano e etanol, as áreas dos picos foi praticamente constante para ambos os tipos de amostra. 

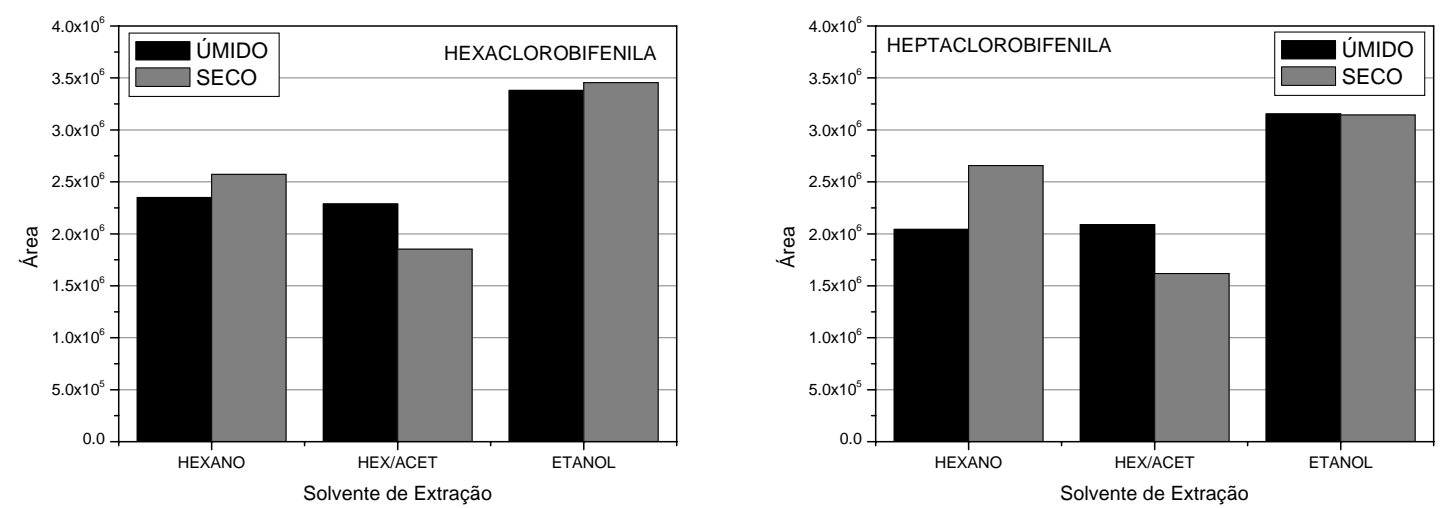

Figura 19: Áreas dos picos para os congêneres hexa e heptaclorobifenila resultantes da extração das amostras seca e úmida com diferentes solventes - hexano, hexano/acetona e etanol

\subsection{ENSAIOS DE OXIDAÇÃO FENTON}

Com o objetivo de degradar o contaminante ascarel em solo usando o processo de oxidação química por meio dos radicais hidroxila gerados pela reação de Fenton, considerou-se a Equação 3 como a reação genérica de degradação calculada a partir do balanço estequiométrico das espécies envolvidas.

$\mathrm{C}_{12} \mathrm{H}_{n} \mathrm{Cl}_{(10-n)}+(n+19) \mathrm{H}_{2} \mathrm{O}_{2} \rightarrow 12 \mathrm{CO}_{2}+(2 n+14) \mathrm{H}_{2} \mathrm{O}+(10-n) \mathrm{HCl} \quad \mathrm{n}=1,2, \ldots, 10$.

Dessa forma, foi admitido que todo ascarel era composto somente de monoclorobifenila $\left(\mathrm{C}_{12} \mathrm{H}_{9} \mathrm{Cl}\right)$, que era o congênere que exigia a maior quantidade de peróxido de hidrogênio, e que esse se mineralizasse em dióxido de carbono $\left(\mathrm{CO}_{2}\right)$ e água $\left(\mathrm{H}_{2} \mathrm{O}\right)$. Partindo-se dessas suposições, calculou-se a quantidade estequiométrica de $\mathrm{H}_{2} \mathrm{O}_{2}$ suficiente para degradar $1 \mathrm{~mol}$ de $\mathrm{C}_{12} \mathrm{H}_{9} \mathrm{Cl}$. O valor obtido foi triplicado, ou seja, foi aplicado ao sistema $\mathrm{H}_{2} \mathrm{O}_{2}$ em excesso para garantir que todo o contaminante fosse degradado. Determinada a quantidade dos reagentes, os mesmos foram aplicados ao sistema reacional uma única vez em regime de batelada, deixando que a reação ocorresse pelo tempo desejado.

Inicialmente, uma batelada de experimentos exploratórios de degradação foi realizada para avaliar a remoção do ascarel do solo em estudo. Para isso, os ensaios foram feitos variando-se a proporção entre os reagentes oxidantes $-\mathrm{H}_{2} \mathrm{O}_{2} \mathrm{e}$ $\mathrm{Fe}^{2+}$. Os valores da razão $\mathrm{Fe}^{2+}: \mathrm{H}_{2} \mathrm{O}_{2}$, nessa ordem, utilizados foram: $A(1: 122), B$ 
(1:60), C (3:122), D (3:60) e E (2:90). Além disso, os experimentos foram realizados nos tempos de reação de 0, 5, 24 e 48 horas. Para avaliar a eficiência do processo de oxidação dos PCBs, também foram escolhidos os mesmos três congêneres (pentaclorobifenila, hexaclorobifenila e heptaclorobifenila) indicados no item 5.2.1. A Figura 20 mostra a remoção de um hexaclorobifenila, que é um dos congêneres de PCB, para os experimentos realizados com 24 horas de reação.

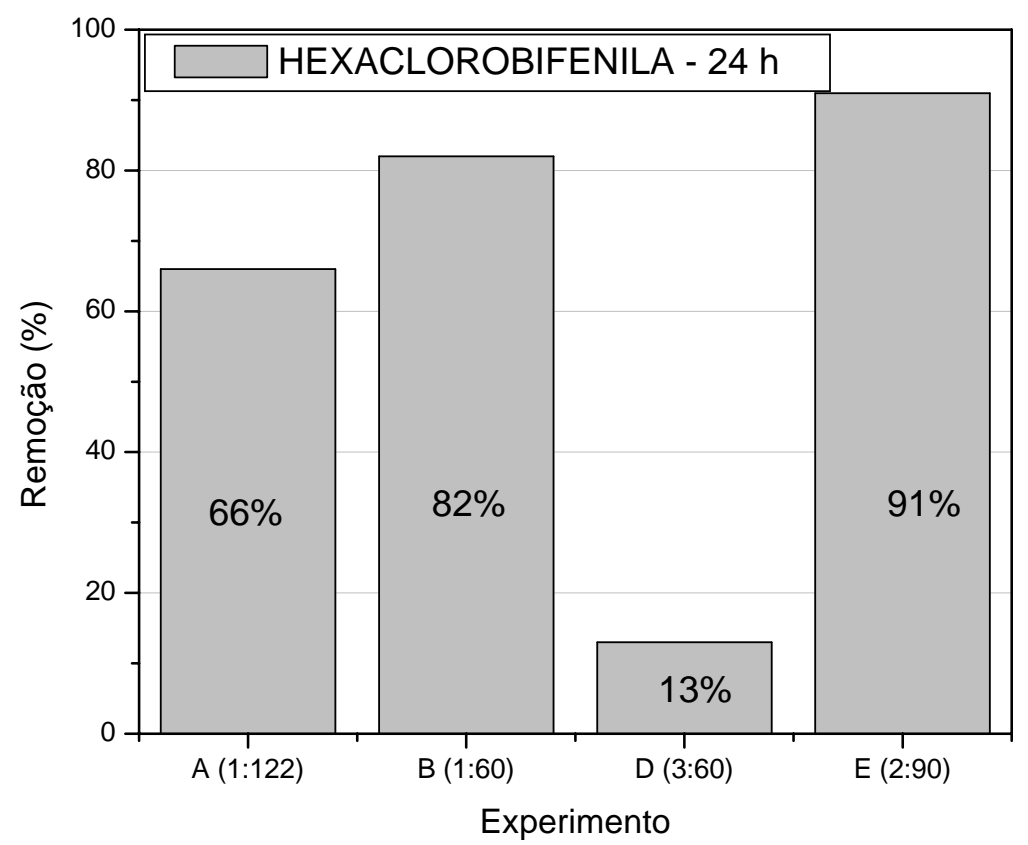

Figura 20: Degradação do hexaclorobifenila, com $24 \mathrm{~h}$ de reação e diferentes quantidades de $\mathrm{H}_{2} \mathrm{O}_{2} \mathrm{e}$ $\mathrm{Fe}^{2+}$

Pelos resultados obtidos, a pior remoção aconteceu no experimento $D$, no qual foi usado $\mathrm{Fe}^{2+}$ e $\mathrm{H}_{2} \mathrm{O}_{2}$ na proporção de 3:60. Isso porque tinha-se, no sistema, menos ferro disponível para a geração de radicais hidroxila que são as espécies oxidantes. Já no experimento $E$ conduzido com os parâmetros de concentração de $0,04: 2,07 \mathrm{~mol} / \mathrm{L}\left(\mathrm{Fe}^{2+}: \mathrm{H}_{2} \mathrm{O}_{2}=2: 90\right)$ e com o tempo de reação de $24 \mathrm{~h}$ houve uma remoção significativa (em torno de 90\%).

Vale salientar que para o melhor experimento, condição E, conseguiu-se atingir significativos percentuais de remoção como indicado no gráfico de barras da Figura 21. Comparando-se os valores dos picos das áreas para os três congêneres - penta, hexa e heptaclorobifenila - para o intervalo de 5 a 48 horas de reação houve remoções iguais ou maiores que $90 \%$, o que é promissor para o processo 
estudado.

A análise cromatográfica realizada nas amostras foi de caráter qualitativo, pois devido à ausência de padrões adequados, não foi possível quantificar os compostos presentes na mistura. A concentração do contaminante usado foi extremamente elevada, aproximadamente $6000 \mathrm{ppm}$, se comparada com os valores que orientam a execução de medidas de tratamento e destruição para qualquer material que contenha um teor acima de 0,12 ppm de PCBs em área industrial (CETESB, 2005).

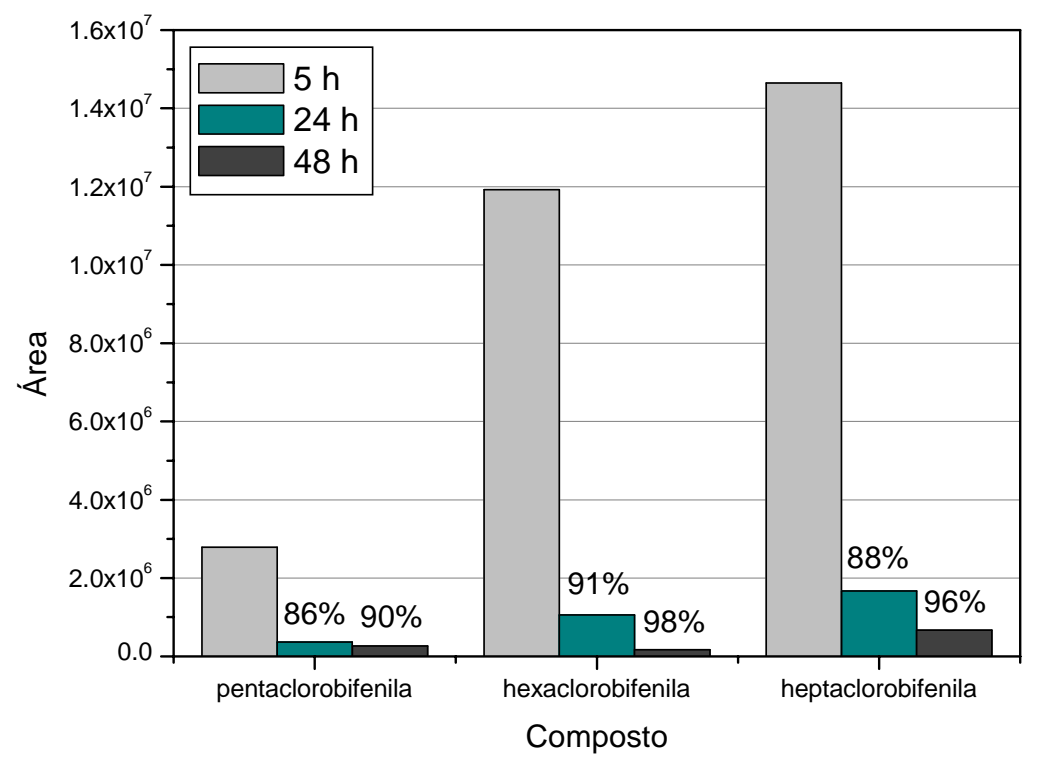

Figura 21: Degradação dos congêneres penta, hexa e heptaclorobifenila com 5, 24 e 48 horas de reação e 2,07 $\mathrm{mol} / \mathrm{L}$ de $\mathrm{H}_{2} \mathrm{O}_{2}$ e $0,04 \mathrm{~mol} / \mathrm{L}$ de $\mathrm{Fe}^{2+}$

Após a análise dos resultados dos experimentos exploratórios, foi realizada uma série sistemática de ensaios experimentais de acordo com a técnica do planejamento experimental fatorial completo $2^{2}$ (dois níveis e duas variáveis com ponto central) conforme a Figura 22, considerando como níveis mínimos as condições do experimento $\mathrm{E}\left(\left[\mathrm{H}_{2} \mathrm{O}_{2}\right]=2,07 \mathrm{~mol} / \mathrm{L} \mathrm{e}\left[\mathrm{Fe}^{2+}\right]=0,04 \mathrm{~mol} / \mathrm{L}\right)$. 


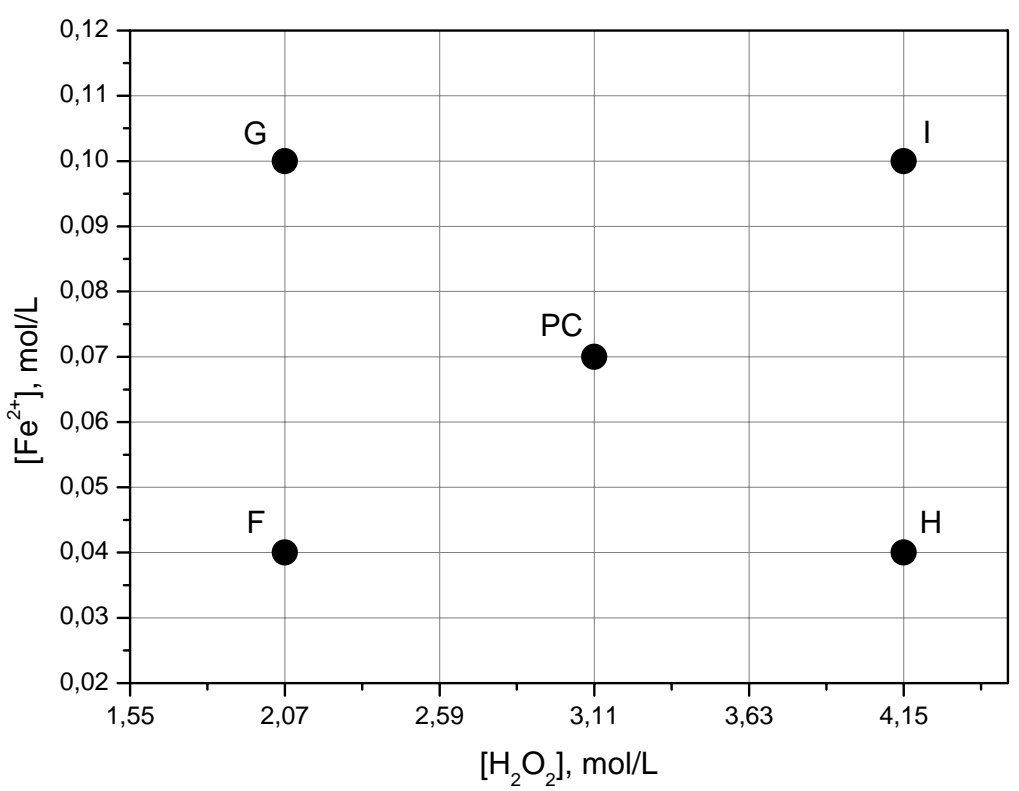

Figura 22: Planejamento experimental fatorial de dois níveis e duas variáveis $\left(2^{2}\right)$

O planejamento experimental teve como objetivo analisar a importância dos efeitos das concentrações de peróxido de hidrogênio e ferro, além do efeito de interação entre essas duas variáveis. Foram então realizados experimentos com 5 (cinco) condições diferentes, como apresentado na Tabela 9, com duplicatas nas condições F, G, H, I e PC (ponto central), para os tempos de reação de 0, 5, 24 e 48 horas, com dois brancos (amostras que não tinham reagente), totalizando 32 ensaios. A concentração de óleo ascarel permaneceu constante para todos os experimentos (6000 ppm = 0,018 gramas de óleo ascarel em 3 gramas de solo).

Os percentuais de remoção obtidos com os experimentos do planejamento experimental encontram-se na Tabela 10. Esses valores foram calculados para o intervalo $0-48$ horas de reação de oxidação do contaminante. Na referida tabela, estão apresentados os valores para os três congêneres modelo: pentaclorobifenila, hexaclorobifenila e heptaclorobifenila. 
Tabela 9:Variáveis absolutas e normalizadas do planejamento experimental

\begin{tabular}{ccccc}
\hline \multirow{2}{*}{$\begin{array}{c}\text { Condição } \\
\text { Experimental }\end{array}$} & \multicolumn{2}{c}{ Valores Absolutos } & \multicolumn{2}{c}{ Valores Normalizados } \\
\cline { 2 - 5 }$\left[\mathrm{H}_{2} \mathrm{O}_{2}\right](\mathbf{m o l} / \mathrm{L})$ & {$\left[\mathrm{Fe}^{2+}\right](\mathbf{m o l} / \mathrm{L})$} & {$\left[\mathrm{H}_{2} \mathrm{O}_{2}\right]$} & {$\left[\mathrm{Fe}^{2+}\right]$} \\
\hline $\mathrm{F}$ & 2,07 & 0,04 & -1 & -1 \\
$\mathrm{G}$ & 2,07 & 0,10 & -1 & +1 \\
$\mathrm{H}$ & 4,15 & 0,04 & +1 & -1 \\
I & 4,15 & 0,10 & +1 & +1 \\
$\mathrm{PC}$ & 3,11 & 0,07 & 0 & 0 \\
\hline
\end{tabular}

Tabela 10: Resultados do planejamento experimental

\begin{tabular}{cccccc}
\hline \multirow{2}{*}{ Condição } & \multicolumn{2}{c}{$\begin{array}{c}\text { Variáveis } \\
\text { Estudadas }\end{array}$} & & Variável Resposta \\
\cline { 2 - 6 } Experimental & & & Remoção (\%) & Remoção (\%) & Remoção (\%) \\
& {$\left[\mathrm{H}_{2} \mathrm{O}_{2}\right]$} & {$\left[\mathrm{Fe}^{2+}\right]$} & hentacloro & hexacloro & heptacloro \\
\hline F & -1 & -1 & 63,09 & 59,07 & 64,75 \\
G & -1 & +1 & 39,29 & 28,37 & 28,82 \\
H & +1 & -1 & 76,04 & 67,51 & 72,01 \\
I & +1 & +1 & 64,69 & 53,62 & 56,39 \\
PC & 0 & 0 & 60,06 & 49,48 & 50,01 \\
PC & 0 & 0 & 53,55 & 42,90 & 46,83 \\
PC & 0 & 0 & 70,24 & 62,53 & 66,36 \\
PC & 0 & 0 & 51,98 & 41,37 & 43,85 \\
\hline
\end{tabular}

Analisando a variável resposta para o pentaclorobifenila, ou seja, o percentual de remoção exposto na Tabela 10 para esse congênere verifica-se que quando se usa o peróxido de hidrogênio na concentração de 2,07 mol/L e eleva-se a concentração de ferro de $0,04 \mathrm{~mol} / \mathrm{L}$ para $0,10 \mathrm{~mol} / \mathrm{L}$, a remoção passa de $63,09 \%$ para 39,29\%. Ocorre, portanto, uma diminuição 23,80\%. Quando a concentração de peróxido de hidrogênio é de 4,15 mol/L, a remoção também diminui de 76,04\% para $64,69 \%$, ou seja, uma redução de $11,35 \%$. Isso mostra que há efeito do peróxido de hidrogênio sobre a remoção de PCBs do sistema quando se eleva essa concentração e que a mesma é dependente da concentração de ferro e vice-versa. Quando a concentração de ferro é de 0,04 mol/L, a mudança de peróxido de hidrogênio eleva de 63,09\% para 76,04\% a remoção do pentaclorobifenila, isto é, 
ocorre um aumento de 12,95\%. Na concentração de 0,10 mol/L de ferro, o aumento é mais significativo e passa de 39,29\% para 64,69\% resultando numa elevação de 25,40\%. Calculando-se o efeito principal do peróxido de hidrogênio - que é por definição a média dos efeitos do peróxido nos dois níveis de ferro - obtém-se 19,18\%. Este valor indica que a remoção sobe 19,18\%, em média, quando a concentração de peróxido passa do seu nível inferior (2,07 mol/L) para seu nível superior $(4,15 \mathrm{~mol} / \mathrm{L})$. Calculando-se o efeito do ferro, obtém-se que a remoção cai 17,58\% em média. Esses valores indicam que há interação entre as duas variáveis estudadas no sistema: concentração de peróxido e concentração de ferro. Se não houvesse interação, o efeito do peróxido de hidrogênio seria o mesmo para qualquer concentração de ferro, isto é, esses dois valores deveriam ser idênticos. Portanto, por definição, o efeito de interação entre essas duas variáveis é a metade da diferença $(25,40 \%$ - 12,95\%)/2 que dá um valor de 6,225\%. Os efeitos das variáveis e suas interações podem ser vistas no gráfico de barras da Figura 23.

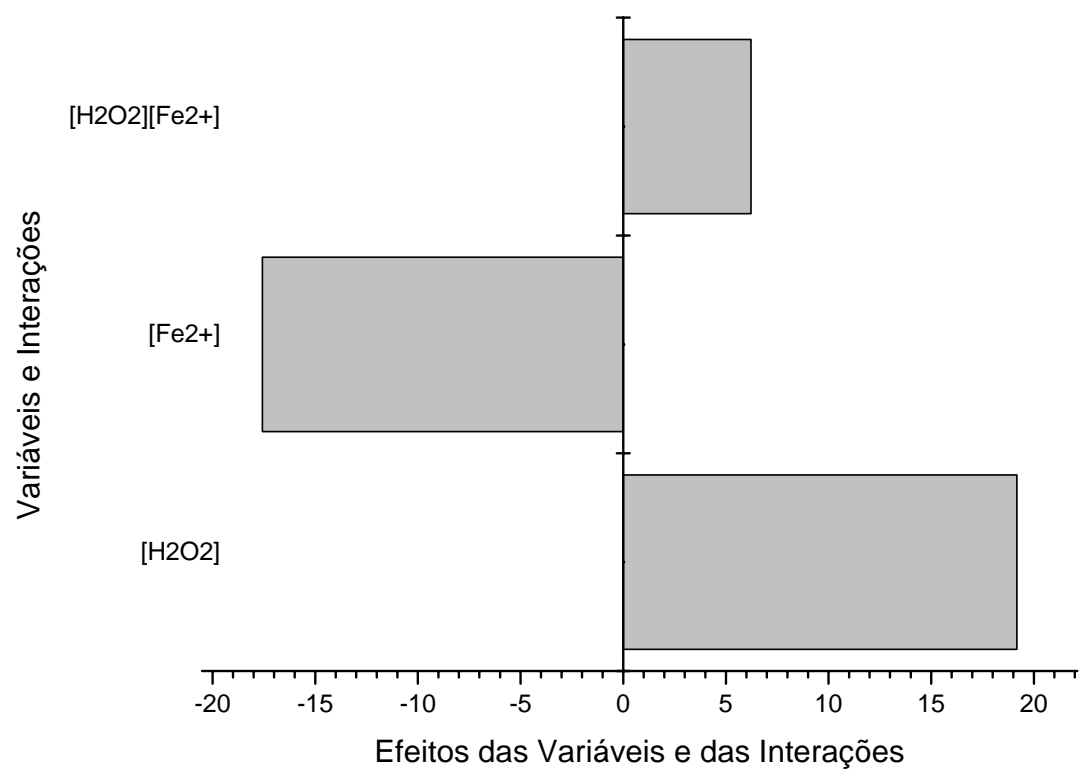

Figura 23: Gráfico de barras dos efeitos das variáveis e suas interações para o pentaclorobifenila

Portanto, pode-se concluir que:

1. Elevando a concentração de peróxido de hidrogênio de 2,07 mol/L para 4,15 $\mathrm{mol} / \mathrm{L}$ aumenta a remoção de PCB, mas o efeito é mais pronunciado quando a 
concentração de ferro sobe de $0,04 \mathrm{~mol} / \mathrm{L}$ para $0,10 \mathrm{~mol} / \mathrm{L}(+12,95 \%$ contra $+25,40 \%)$;

2. Aumentando-se a concentração de ferro diminui-se o percentual de remoção. E esse efeito é mais significativo a 2,07 mol/L de peróxido que 4,15 mol/L ($23,80 \%$ contra $-11,35 \%)$. O efeito negativo dessa variável indica que a quantidade de ferro usada no sistema pode ser reduzida, implicando em um menor custo, sem prejuízo no valor do percentual de remoção;

3. A maior remoção $(76,04 \%)$ é obtida com a concentração de ferro de 0,04 $\mathrm{mol} / \mathrm{L}$ e com a concentração de peróxido de hidrogênio de 4,15 mol/L (condição $\mathrm{H}$ do planejamento experimental).

Essas observações podem ser visualizadas no gráfico da Figura 24 para os três congêneres de referência. Vale ressaltar que o comportamento observado no pentaclorobifenila se repete para os outros dois congêneres modelo: hexaclorobifenila e heptaclorobifenila. Por isso, a análise realizada para o pentaclorobifenila pode ser ampliada para o sistema como um todo.

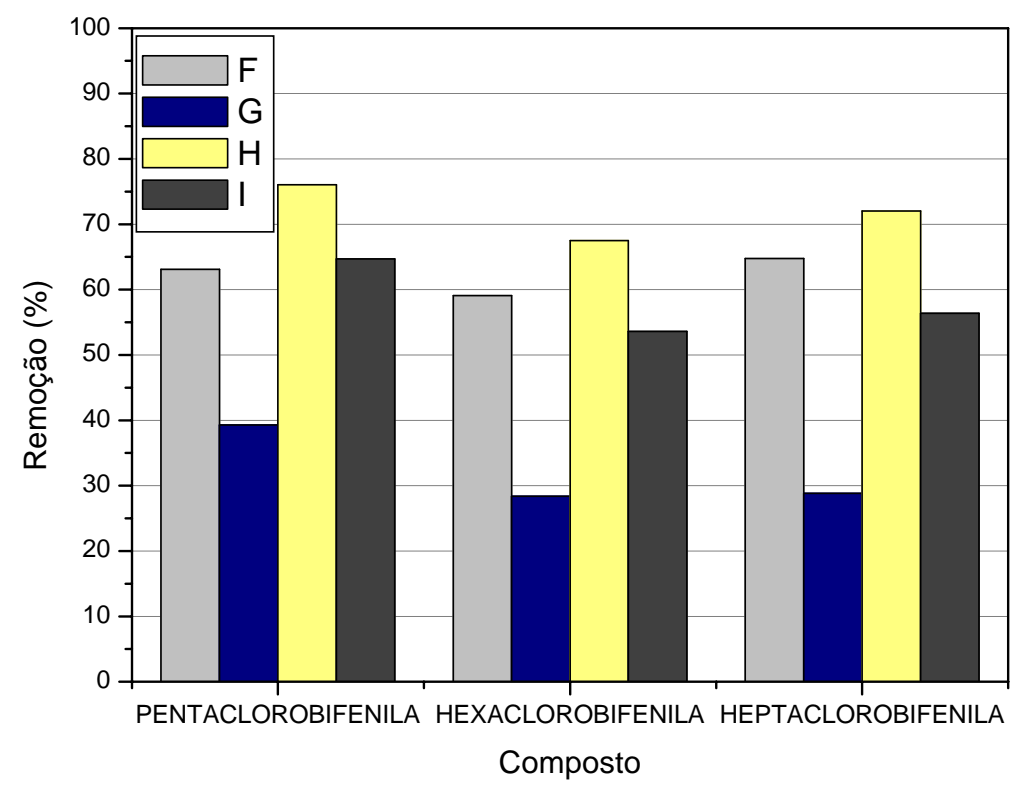

Figura 24: Percentual de remoção de congêneres de PCBs em 48 horas de reação nas condições $F$, $\mathrm{G}, \mathrm{H}$ e I do planejamento experimental

Para avaliar o grau de reprodutibilidade do procedimento experimental adotado, foram realizadas quatro repetições no ponto central (PC) do planejamento 
experimental. Na Tabela 11 pode ser visto as repetições e seus respectivos percentuais de remoção para os três congêneres, representados graficamente na Figura 25.

Tabela 11: Percentuais de remoção na condição experimental do ponto central para os três congêneres (penta, hexa e heptaclorobifenila)

\begin{tabular}{cccc} 
Condição & pentaclorobifenila & hexaclorobifenila & heptaclorobifenila \\
\cline { 2 - 4 } Experimental & Remoção (\%) & Remoção (\%) & Remoção (\%) \\
\hline PC-1 & 60,06 & 49,48 & 50,01 \\
PC-2 & 53,55 & 42,90 & 46,83 \\
PC-3 & 70,24 & 62,53 & 66,36 \\
PC-4 & 51,98 & 41,37 & 43,85 \\
\hline
\end{tabular}

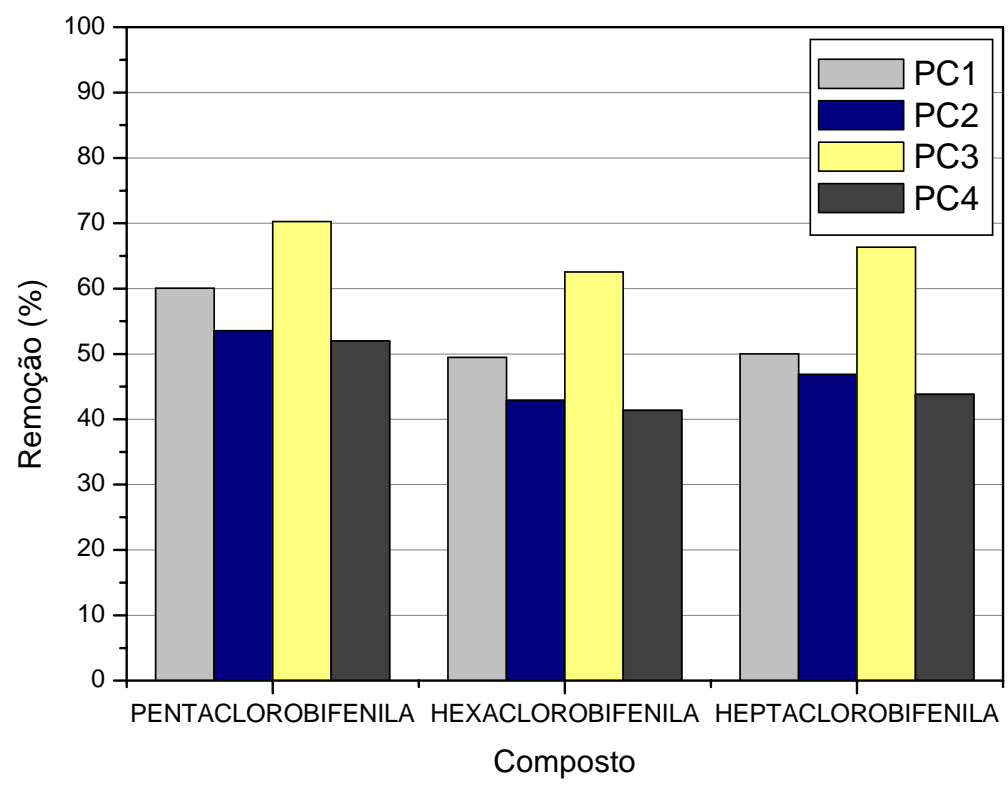

Figura 25: Percentual de remoção dos congêneres de PCBs no experimento na condição do ponto central para 48 horas de reação

Pode-se observar que os percentuais de remoção encontram-se dentro de um intervalo médio com exceção do terceiro ponto (PC-3) que teve um valor muito distante dos outros. Pode-se afirmar, portanto, que os experimentos são reprodutivos se eliminarmos esse terceiro ponto.

Considerando que os pontos centrais se distribuem normalmente, pode-se determinar um intervalo de confiança para verificar se o PC-3 pode ou não ser 
incluído na análise estatística dos resultados. Aplicando a distribuição normal z sobre os dados do ponto central, defini-se numericamente os limites do intervalo de confiança aplicando-se a expressão representada pela Equação 4 abaixo:

$\bar{x}-z \cdot \frac{\sigma}{\sqrt{N}}<\mu<\bar{x}+z \cdot \frac{\sigma}{\sqrt{N}}$

Onde:

$\bar{X}=$ média da amostra;

$z$ = variável padronizada da distribuição normal;

$\mu=$ média populacional;

$\sigma / \sqrt{N}=$ desvio padrão da amostra.

Os respectivos intervalos de confiança referentes aos dados da Tabela 11 que justificam a exclusão do PC-3, com 95\% de confiança e z igual a 1,96, são:

Pentaclorobifenila: 50,83\% $<\mu<67,09 \%$;

Hexaclorobifenila: $39,62 \%<\mu<58,52 \%$;

Heptaclorobifenila: $41,91 \%<\mu<61,61 \%$;

Diante dos intervalos de confiança dos três congêneres, pode-se afirmar que o valor de PC-3 deve ser excluído da análise estatística dos dados.

Para obter a superfície de resposta dos dados do planejamento experimental (Tabela 10), sem o PC-3, é necessário aplicar um modelo. Dessa forma, foram testados três modelos, representados pelas Equações 5 - 13, para verificar qual deles se ajustaria melhor aos dados. Nos modelos propostos, as variáveis $a_{0}, a_{1}, a_{2}$ e $a_{3}$ são os parâmetros do modelo, $x_{1}$ (concentração de peróxido de hidrogênio) e $x_{2}$ (concentração de ferro) representam as variáveis estudadas normalizadas e y é o percentual de remoção dos congêneres de referência. A seguir encontram-se os modelos propostos para os três congêneres de referência: penta, hexa e heptaclorobifenila. 
- Modelo 1: Linear $\left(y=a_{0}+a_{1} \cdot x_{1}+a_{2} \cdot x_{2}+a_{3} \cdot x_{1} \cdot x_{2}\right)$

$y_{\text {penta }}=58,39+9,59 \cdot x_{1}-8,79 \cdot x_{2}+3,11 \cdot x_{1} \cdot x_{2}$

$y_{\text {hexa }}=48,90+8,42 \cdot x_{1}-11,15 \cdot x_{2}+4,20 \cdot x_{1} \cdot x_{2}$

$y_{\text {hepta }}=51,81+8,71 \cdot x_{1}-12,89 \cdot x_{2}+5,10 \cdot x_{1} \cdot x_{2}$

- Modelo 2: Polinomial $\left(y=a_{0} \cdot x_{1}+a_{1} \cdot x_{2}^{2}+a_{2} \cdot x_{1} \cdot x_{2}+a_{3}\right)$

$y_{\text {penta }}=9,59 \cdot x_{1}+5,58 \cdot x_{2}^{2}+3,11 \cdot x_{1} \cdot x_{2}+55,20$

$\mathrm{y}_{\text {hexa }}=8,42 \cdot \mathrm{x}_{1}+7,56 \cdot \mathrm{x}_{2}{ }^{2}+4,20 \cdot \mathrm{x}_{1} \cdot \mathrm{x}_{2}+44,58$

$\mathrm{y}_{\text {hepta }}=8,71 \cdot \mathrm{x}_{1}+8,60 \cdot \mathrm{x}_{2}{ }^{2}+5,10 \cdot \mathrm{x}_{1} \cdot \mathrm{x}_{2}+46,90$

- Modelo 3: Polinomial $\left(y=a_{0} \cdot x_{1}{ }^{2}+a_{1} \cdot x_{2}+a_{2} \cdot x_{1} \cdot x_{2}+a_{3}\right)$

$y_{\text {penta }}=5,58 \cdot x_{1}^{2}-8,79 \cdot x_{2}+3,11 \cdot x_{1} \cdot x_{2}+55,20$

$y_{\text {hexa }}=7,56 \cdot x_{1}^{2}-11,15 \cdot x_{2}+4,20 \cdot x_{1} \cdot x_{2}+44,58$

$\mathrm{y}_{\text {hepta }}=8,60 \cdot \mathrm{x}_{1}^{2}-12,89 \cdot \mathrm{x}_{2}+5,10 \cdot \mathrm{x}_{1} \cdot \mathrm{x}_{2}+46,90$

Atribuindo-se os valores das concentrações normalizadas do planejamento experimental nas Equações 5 - 13, obtêm-se os percentuais de remoção calculados pelos modelos sugeridos. Estes valores podem ser vistos nas Tabelas 12, 13 e 14. O PC usado foi a média de PC-1, PC-2 e PC-4.

Tabela 12: Percentuais de remoção experimental e calculados para o pentaclorobifenila

\begin{tabular}{ccccccc}
\hline \multirow{2}{*}{$\begin{array}{c}\text { Condição } \\
\text { Experimental }\end{array}$} & \multicolumn{2}{c}{ Variáveis } & \multicolumn{3}{c}{ Modelos Testados } & Experimental \\
\cline { 2 - 6 } & $\mathbf{x}_{1}$ & $\mathbf{x}_{2}$ & $\mathbf{M}-1$ & $\mathbf{M}-2$ & $\mathbf{M}-3$ & y\% \\
\hline F & -1 & -1 & 60,70 & 54,30 & 72,68 & 63,09 \\
G & -1 & +1 & 36,90 & 48,10 & 48,88 & 39,29 \\
H & +1 & -1 & 73,65 & 67,25 & 66,46 & 76,04 \\
I & +1 & +1 & 62,30 & 73,48 & 55,10 & 64,69 \\
PC & 0 & 0 & 58,39 & 55,20 & 55,20 & 55,20 \\
\hline
\end{tabular}


Tabela 13: Percentuais de remoção experimental e calculados para o hexaclorobifenila

\begin{tabular}{ccccccc}
\hline \multirow{2}{*}{$\begin{array}{c}\text { Condição } \\
\text { Experimental }\end{array}$} & \multicolumn{2}{c}{ Variáveis } & \multicolumn{3}{c}{ Modelos Testados } \\
\cline { 2 - 6 } & $\mathbf{x}_{\mathbf{1}}$ & $\mathbf{x}_{\mathbf{2}}$ & $\mathbf{M}-\mathbf{1}$ & $\mathbf{M}-\mathbf{2}$ & $\mathbf{M}-3$ & Experimental \\
\cline { 2 - 6 } F & -1 & -1 & 55,83 & 47,92 & 67,49 & 59,07 \\
G & -1 & +1 & 25,13 & 39,52 & 36,79 & 28,37 \\
H & +1 & -1 & 64,27 & 56,36 & 59,09 & 67,51 \\
I & +1 & +1 & 50,38 & 64,77 & 45,20 & 53,62 \\
PC & 0 & 0 & 48,90 & 44,58 & 44,58 & 44,58 \\
\hline
\end{tabular}

Tabela 14: Percentuais de remoção experimental e calculados para o heptaclorobifenila

\begin{tabular}{ccccccc}
\hline \multirow{2}{*}{$\begin{array}{c}\text { Condição } \\
\text { Experimental }\end{array}$} & \multicolumn{2}{c}{ Variáveis } & \multicolumn{3}{c}{ Modelos Testados } \\
\cline { 2 - 6 } & $\mathbf{x}_{\mathbf{1}}$ & $\mathbf{x}_{\mathbf{2}}$ & $\mathbf{M}-\mathbf{1}$ & $\mathbf{M}-\mathbf{2}$ & $\mathbf{M}-3$ & Experimental \\
\cline { 2 - 6 } F & -1 & -1 & 61,07 & 51,86 & 73,46 & 64,75 \\
G & -1 & +1 & 25,14 & 41,71 & 37,53 & 28,82 \\
H & +1 & -1 & 68,33 & 59,12 & 63,30 & 72,01 \\
I & +1 & +1 & 52,71 & 69,28 & 47,68 & 56,39 \\
PC & 0 & 0 & 51,81 & 46,90 & 46,90 & 46,90 \\
\hline
\end{tabular}

Cada modelo foi avaliado confrontando os valores experimentais com os valores estimados pelo respectivo modelo, conforme apresentado nas Figuras 26, 27 e 28, para os três congêneres. Os Modelos 2 e 3 não foram capazes de representar o sistema adequadamente, apresentando como melhor correlação $R^{2}=0,7316$. Entretanto, verificou-se que o Modelo 1 apresentou o melhor ajuste entre os dados experimentais e calculados, sendo obtidos os seguintes valores de coeficiente de correlação linear: 0,965 (penta), 0,947 (hexa) e 0,946 (hepta), indicando que o Modelo 1 foi capaz de representar o fenômeno de remediação de solos contaminados por bifenilas policloradas via processo Fenton. 
Usando-se as equações do Modelo 1, referentes aos três congêneres de referência, foram obtidas as respectivas superfícies de resposta, variando-se as concentrações de ferro e de peróxido de hidrogênio ao longo dos seus níveis mínimos e máximos, obtendo-se a melhor condição operacional dentro do domínio experimental estudado $\left(\left[\mathrm{Fe}^{2+}\right]=0,04 \mathrm{~mol} / \mathrm{L}\right.$ e $\left.\left[\mathrm{H}_{2} \mathrm{O}_{2}\right]=4,15 \mathrm{~mol} / \mathrm{L}\right)$, conforme apresentado nas Figuras 28, 29 e 30.

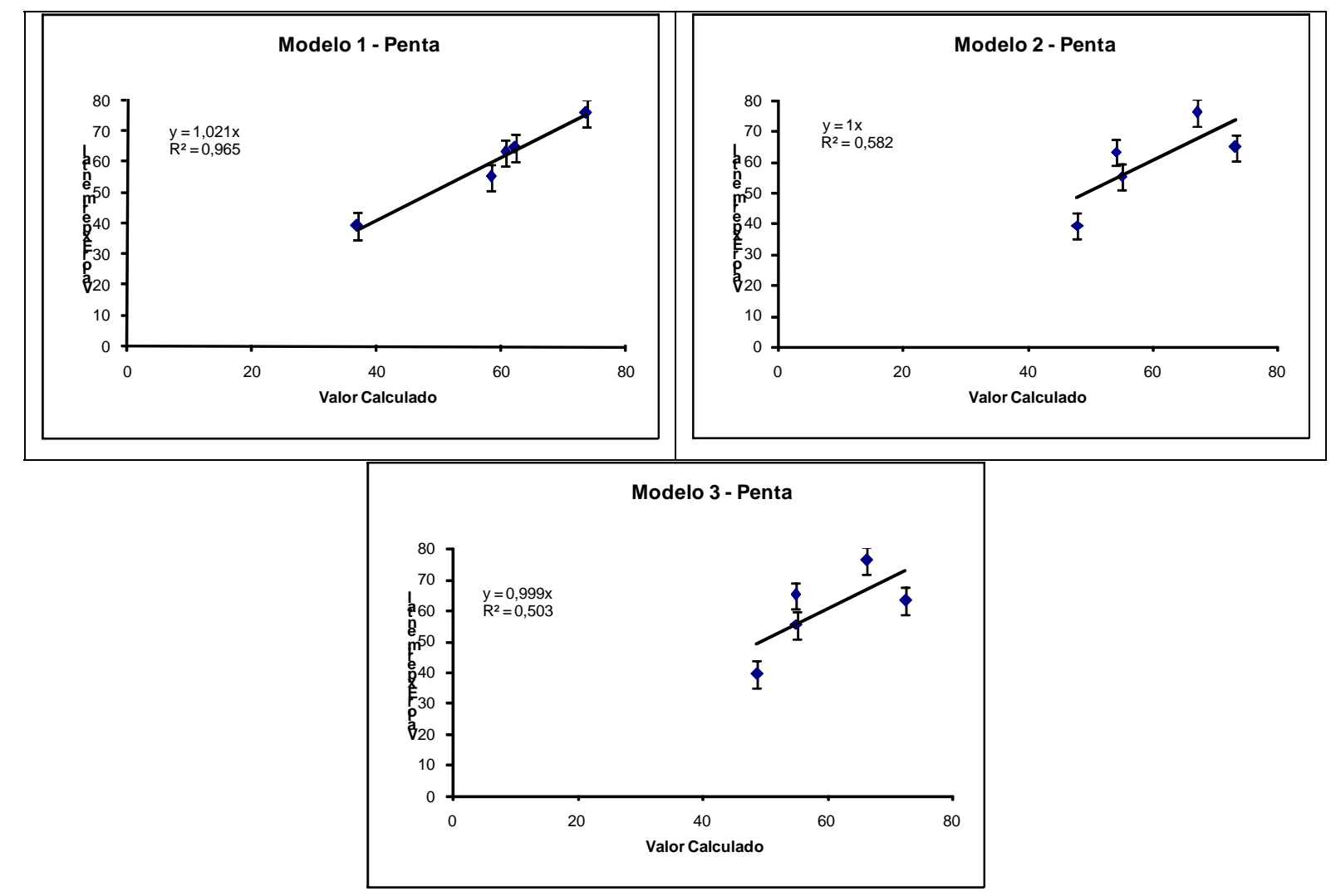

Figura 26: Modelos 1, 2 e 3 propostos para ajuste dos dados do pentaclorobifenila 

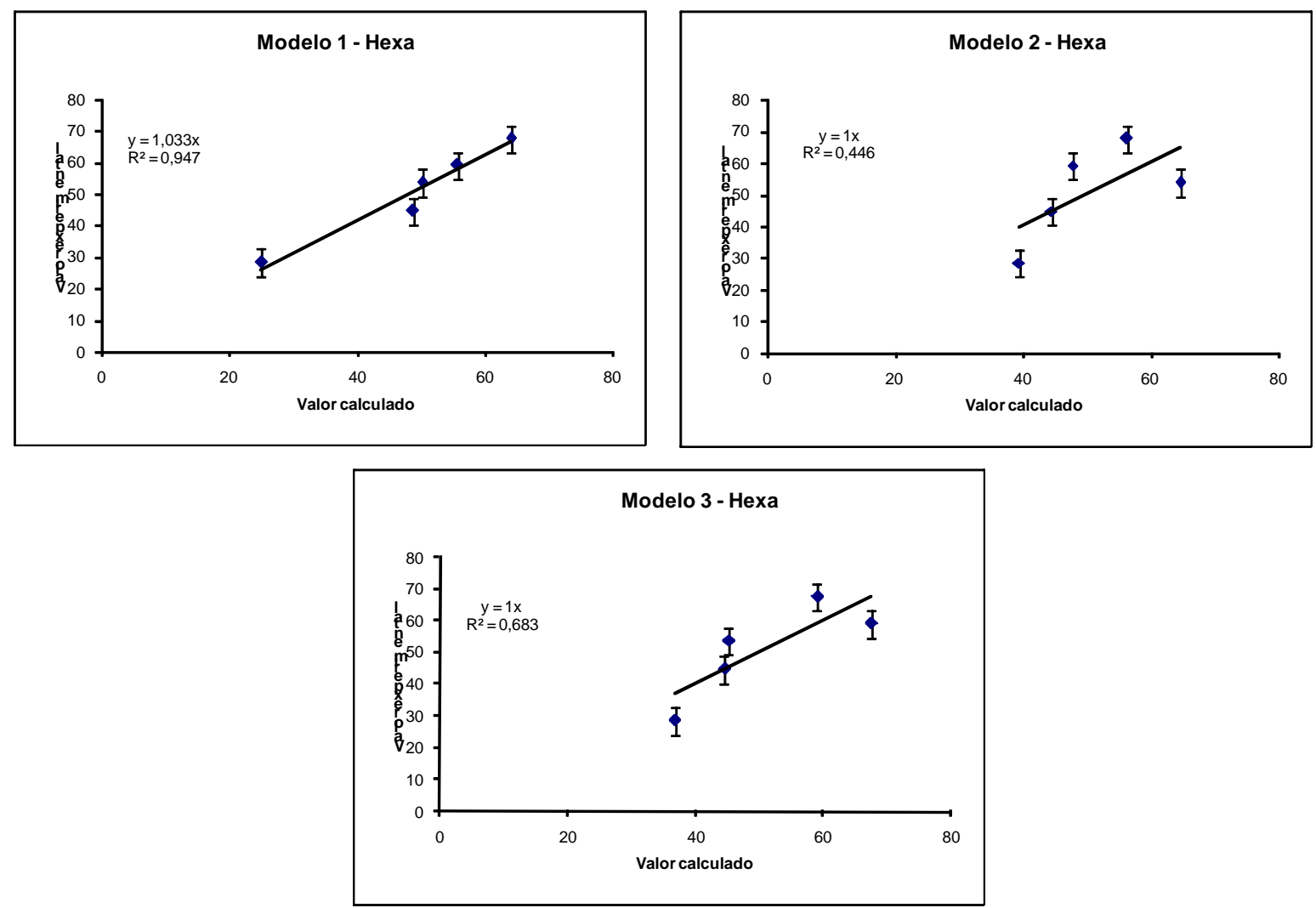

Figura 27: Modelos 1, 2 e 3 propostos para ajuste dos dados do hexaclorobifenila
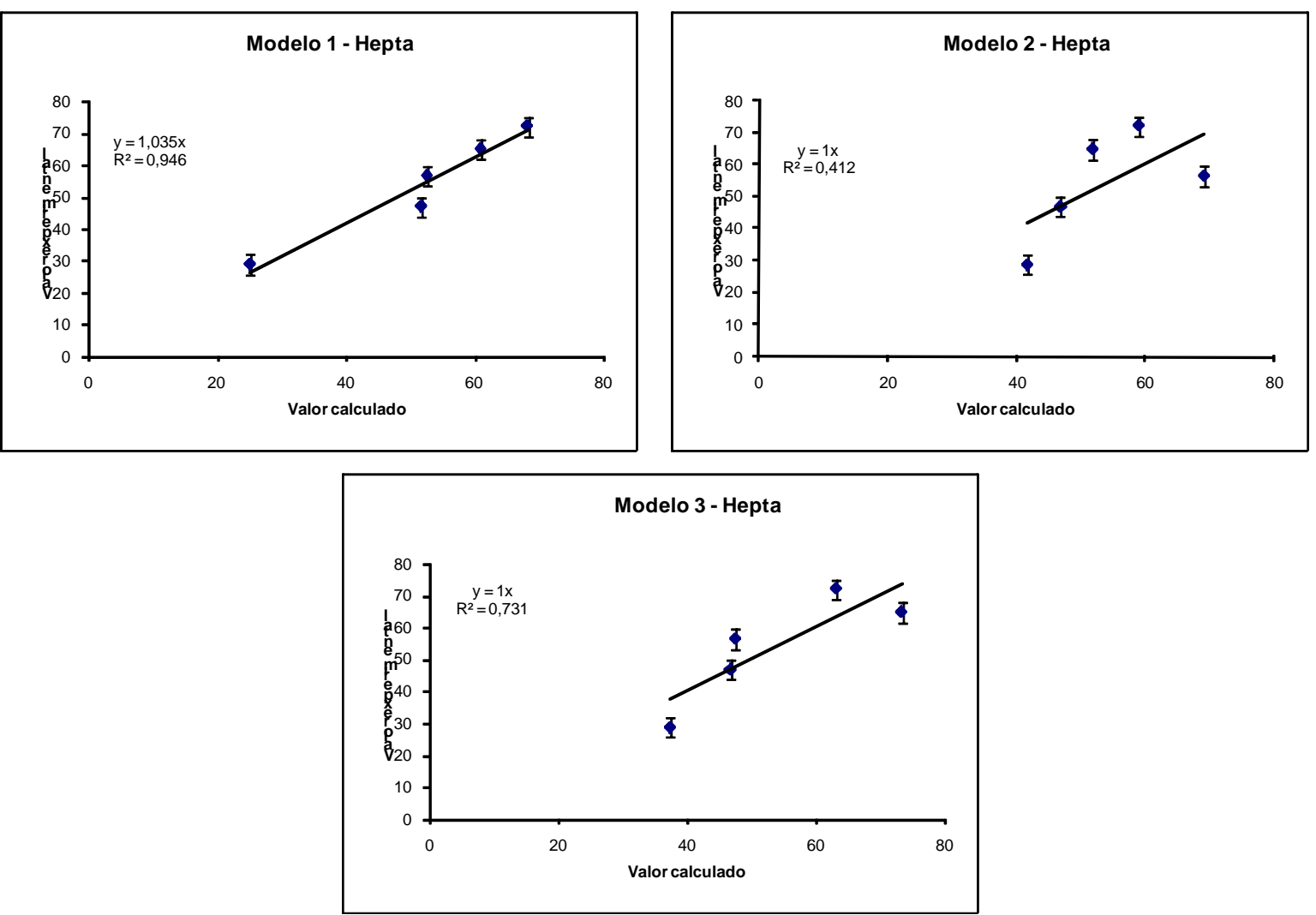

Figura 28: Modelos 1, 2 e 3 propostos para ajuste dos dados do heptaclorobifenila 
Usando-se as equações do Modelo 1, referentes aos três congêneres de referência, foram obtidas as respectivas superfícies de resposta, variando-se as concentrações de ferro e de peróxido de hidrogênio ao longo dos seus níveis mínimos e máximos, obtendo-se a melhor condição operacional dentro do domínio experimental estudado $\left(\left[\mathrm{Fe}^{2+}\right]=0,04 \mathrm{~mol} / \mathrm{L}\right.$ e $\left.\left[\mathrm{H}_{2} \mathrm{O}_{2}\right]=4,15 \mathrm{~mol} / \mathrm{L}\right)$, conforme apresentado nas Figuras 29, 30 e 31.

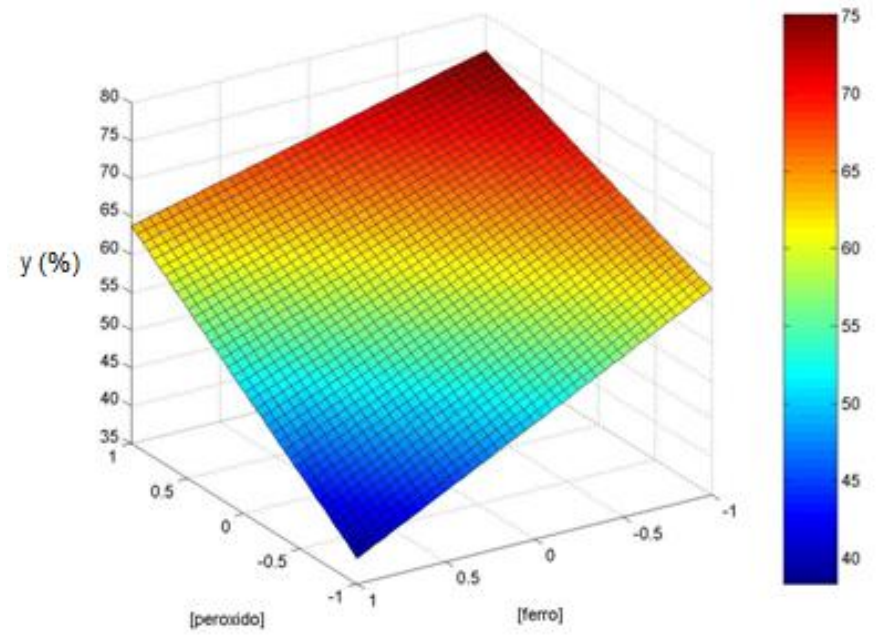

Figura 29: Superfície de resposta referente ao pentaclorobifenila

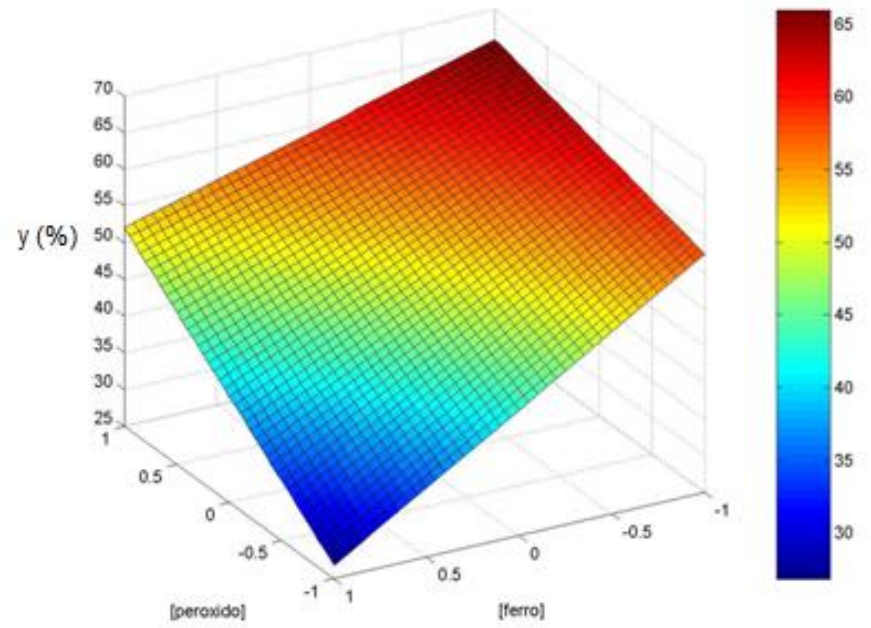

Figura 30: Superfície de resposta referente ao hexaclorobifenila 


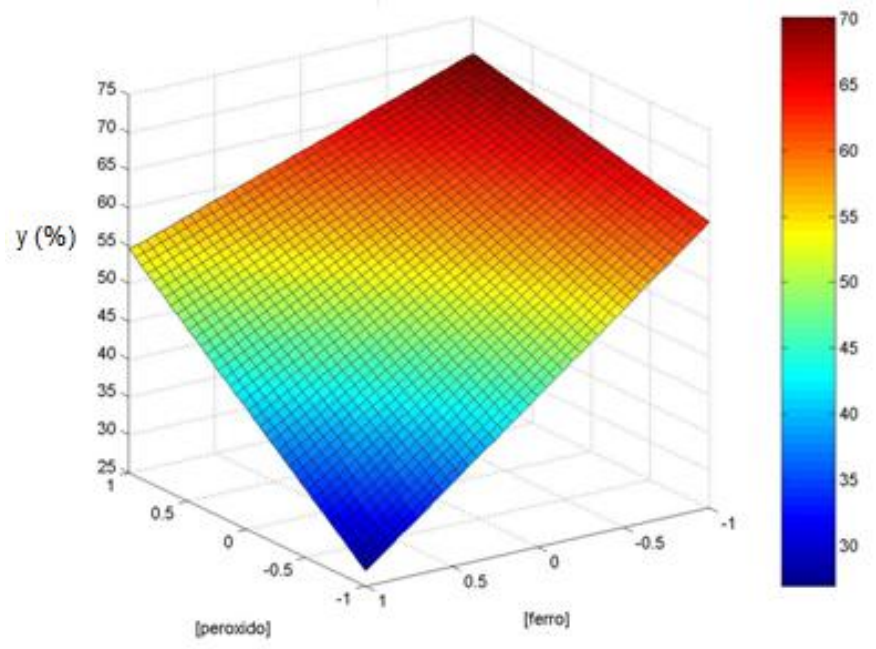

Figura 31: Superfície de resposta referente ao heptaclorobifenila 


\section{CONCLUSÕES}

Dos resultados obtidos dos experimentos realizados, pode-se concluir que:

- A quantidade de orgânicos presentes originalmente no solo bruto, em torno de $8 \%$, não foi suficiente para influenciar no estudo da quantificação dos efeitos das concentrações de ferro e de peróxido, dentro da região experimental estudada;

- Pela granulometria do solo utilizado, conclui-se que é um solo predominantemente arenoso. Nesse tipo de solo, a adsorção do contaminante na matriz é menos intensa, já que essa é facilitada pela quantidade de argilas e matéria orgânica do meio;

- O valor de área superficial específica de $24,52 \mathrm{~m}^{2} / \mathrm{g}$ é um valor baixo para adsorção dos contaminantes ao solo. Era um valor esperado pois se trabalhou com um solo arenoso, ou seja, de partículas maiores e que dificultam o fenômeno da adsorção;

- Utilizando extração Soxhlet, o tempo de extração adotado nos experimentos foi de 7 horas. Isso foi determinado através dos ensaios realizados para determinar o melhor tempo. Nesses ensaios, entre 3 e 4 horas de extração os valores das áreas dos picos apresentaram pequenas variações, o que nos permitiu extrapolar para 7 horas, garantindo que 0 máximo de contaminante seria extraído;

- Ao longo da execução do projeto de pesquisa foi utilizado dois diferentes equipamentos de extração automáticos Soxhlet. Com essa mudança os resultados se mostraram melhores no equipamento da Gerhardt do que os da TECNAL. No equipamento da TECNAL, a umidade residual das amostras de solo advindas da etapa de filtração dificultava a transferência do contaminante da fase sólida para o extrato, diminuindo, dessa forma, a eficiência da extração. Nos resultados obtidos pelo equipamento da Gerhardt esse fenômeno não aconteceu, ou seja, o equipamento conseguiu reduzir essa interferência na etapa de extração. Os resultados 
das extrações para as amostras úmidas e secas foram praticamente semelhantes para os três solventes testados: n-hexano, n-hexano/acetona, etanol.

- Nos ensaios realizados com diferentes solventes, podemos concluir que os melhores resultados foram obtidos utilizando o álcool etílico como solvente. Esse fato merece destaque já que diversos processos de extração aplicados comercialmente utilizam grandes quantidades de solventes mais caros e mais tóxicos que o etanol como o n-hexano, a acetona e o diclorometano;

- No primeiro conjunto de experimentos exploratórios, o melhor resultado obtido aconteceu nas concentrações de 2,07 mol/L de $\mathrm{H}_{2} \mathrm{O}_{2}(30 \%)$ e 0,04 $\mathrm{mol} / \mathrm{L}$ de $\mathrm{Fe}^{2+}$. Nesses parâmetros de reação atingiram-se resultados promissores, obtendo-se percentuais de remoção em torno de 90\%;

- Partindo da condição obtida acima, após a aplicação dos ensaios do planejamento experimental podemos concluir que o sistema que apresentou melhor remoção de PCBs, cerca de $76 \%$ para 0 pentaclorobifenila, foi o do ponto $\mathrm{H}$, cujas condições experimentais eram: $4,15 \mathrm{~mol} / \mathrm{L}$ de $\mathrm{H}_{2} \mathrm{O}_{2}$ e $0,04 \mathrm{~mol} / \mathrm{L}$ de $\mathrm{Fe}^{2+}$;

- A concentração de $\mathrm{Fe}^{2+}$ no sistema de oxidação Fenton foi a variável que apresentou maior efeito, porém afetando negativamente o processo de degradação, em oposição ao efeito da concentração de $\mathrm{H}_{2} \mathrm{O}_{2}$ que foi aproximadamente duas vezes menor. Isso significa que a [Fe2+] no sistema pode ser diminuído sem redução do percentual de remoção no processo de oxidação;

- É necessário trabalhar com um maior número de amostras para que os experimentos de oxidação realizados sejam mais representativos do sistema como um todo, pois o solo é um sistema complexo e bastante heterogêneo, o que dificulta a repetibilidade dos resultados. 


\section{REFERÊNCIAS}

ABETRE. É Necessário uma Legislação Mais Clara para Áreas Contaminadas. Disponível em: http://www.portaldogrito.org.br/arquivos multimidia/42.doc. Acesso em: 24 de março. 2004.

ALMEIDA, G. Tecnologias de Tratamento de Solos Contaminados. Disponível em: http://users.med.up.pt/faru/solos tec descont.htm. Acesso em: 05 de julho. 2005.

AMBICARE. Documento Técnico "PCB O QUE SÃO?" Disponível em: http://www.ambicare.com/downloads/documento ambicare pcb.pdf. Acesso em: 04 de junho. 2005.

ANTONELLO, I.; SAPELLI, E.; SILVA, P. B.; SILVA, D.; MARTINS, A. R.; HUMERES, E.; SOUZA, I. G.; DEBACHER, N. A. Métodos de determinação e eliminação de ascarel no óleo isolante de transformadores. In: CONGRESSO BRASILEIRO DE INOVAÇÃO TECNÓLICA EM ENERGIA ELÉTRICA, 3., 2005, Florianópolis. Anais... Florianópolis: Prospect. 1 CD-ROM. 2005.

BACKE, C.; COUSINS, I. T.; LARSSON, P. PCB in soils and estimated soil-air exchange fluxes of selected PCB congeners in the south of Sweden. Environmental Pollution. 128, 59-72, 2004.

BAETA, Z. TJ determina que Eletropaulo recupere área poluída em SP. Valor Econômico, 10 jun. 2003. Legislação \& Tributos.

BANDH, C.; BJÖRKLUND, E.; NÄF, K.; ZEBÜHR, Y. Comparison of accelerated solvent extraction and Soxhlet extraction for determination of PCBs in Baltic Sea sediments. Environ. Sci. Technol. 34, 4995-5000, 2000.

BOGAN, B. W.; TRBOVIC, V. Effect of sequestration on PAH degradability with Fenton's reagent: roles of total organic carbon, humin, and soil porosity. Journal of Hazardous Materials B. 100, 285-300, 2003.

BORJA, J.; TALEON, D. M.; AURESENIA, J.; GALLARDO, S. Polychlorinated biphenyls and their biodegradation. Process Biochemistry. 40, 1999-2013, 2005.

BREIVIK, K.; ALCOCK, R.; LI, Y.; BAILEY, R. E.; FIEDLER, H.; PACYNA, J. M. Primary sources of selected POPs: regional and global scale emission inventories. Environmental Pollution. 128, 3-6, 2004.

BREUS, I. P.; MISHCHENKO, A. A.; POTASHEV, K. A.; BREUS, V. A. Description of organic compound vapor-phase sorption by geosorbents: adequacy of the isotherm approximation. Colloids and Surfaces A: Physicochem. Eng. Aspects. 276, 122-133, 2006. 
CETESB. Valores Orientadores para Solos e Águas Subterrâneas no Estado de São Paulo. Disponível em: http://www.cetesb.sp.gov.br/Solo/relatorios/tabela valores 2005.pdf. Acesso em: 4 de junho. 2005.

CETESB. Manual de Produtos Químicos Perigosos - Ficha de Informação de Produto Químico. Disponível em: http://www.cetesb.sp.gov.br/Emergencia/produtos/ficha completa1.asp. Acesso em: 17 de abril. 2006.

CETESB. Relação de Áreas Contaminadas. Disponível em: http://www.cetesb.sp.gov.br/Solo/areas contaminadas/relacao areas.asp. Acesso em: 02 de julho. 2007.

COSTA, A. F. U.; AZAMBUJA, E.; NANNI, A. S. Métodos elétricos aplicados à detecção da contaminação do subsolo provocada por combustíveis no Rio Grande do Sul, Brasil. 6th International Congresso of the Brazilian Geophysical Society, Rio de Janeiro, Brasil, 1999.

DERCOVÁ, K.; VRANA, B.; TANDLICH, R.; SUBOVÁ, L. Fenton's type reaction and chemical pretreatment of PCBs. Chemosphere. 39(15), 2621-2628, 1999.

ECKHARDT, S.; BREIVIK, K.; MANO, S.; STOHL, A. Record high peaks in PCB concentrations in the Arctic atmosphere due to long-range transport of biomass burning emissions. Atmospheric Chemistry and Physics Discussions. 7, 6229 - 6254, 2007.

ELI. An Analysis of State Superfund Programs: 50-State Study. Disponível em: http://www.elistore.org/reports detail.asp?ID=10746. Acesso em: 25 de novembro. 2007.

FILIMONOVA, S. V.; KNICKER, H.; KÖGEL-KNABNER, I. Soil micro- and mesopores studied by $\mathrm{N}_{2}$ adsorption and 129Xe NMR of adsorbed xenon. Geoderma. 130, 218-228, 2006.

FLOTRON, V.; DELTEIL, C.; PADELLEC, Y.; CAMEL, V. Removal of sorbed polycyclic aromatic hydrocarbons from soil, sludge and sediment samples using the Fenton's reagent process. Chemosphere. 59, 1427-1437, 2005.

FRTR. Abstracts of Remediation Case Studies. Disponível em: http://www.frtr.gov/pdf/volume11\%20Final\%202007.pdf. Acesso em: 13 de junho. 2007.

GABEIRA, F. Poder legislativo. In: TRIGUEIRO, A. (Coord.). Meio ambiente no século 21: 21 especialistas falam da questão ambiental nas suas áreas de conhecimento. 1. ed. Rio de Janeiro: Sextante, 2003. p. 275-285.

GARCÍA-ALONSO, S.; PÉREZ-PASTOR, R. M. Occurrence of PCBs in ambient air and surface soil in an urban site of Madrid. Water, Air and Soil Pollution. 146, 283295, 2003. 
GREENPEACE. Critérios técnicos para a destruição de estoques de poluentes orgânicos persistentes. Disponível em: http://www.greenpeace.org.br/toxicos/pdf/crittecnicos.pdf. 1998.

GREENPEACE. Poluentes orgânicos persistentes: poluição invisível e global. Disponível em: http://www.greenpeace.org.br/toxicos/pdf/poluentes.pdf. Acesso em: 02 de abril. 2005.

HIGARASHI, M. M. Processo oxidativos avançados aplicados à remediação de solos brasileiros contaminados com pesticidas. 71p. Tese de Doutorado - Unicamp, Campinas, 1999.

JAKHER, A. Technological advancements in the development of photochemical remediation for polychlorinated biphenyl contaminated soils. 308p. Ph.D. University of Calgary, Canadá, 2007.

KASTÁNEK, F.; KASTÁNEK, P. Combined decontamination processes for wastes containing PCBs. Journal of Hazardous Materials B. 117, 185-205, 2005.

KILE, D. E.; CHIOU, C. T.; ZHOU, H.; LI, H.; XU, O. Partition of nonpolar organic pollutants from water to soil and sediment organic matters. Environ. Sci. Technol. 29, 1401-1406, 1995.

KUEPER, B. H.; WEALTHALL, G. P.; SMITH, J. W. N.; LEHARNE, S. A.; LERNER, D. N. An illustrated handbook of DNAPL transport and fate in the subsurface. Environment Agency R\&D Publication 133, UK, 2003.

KUO, W. G. Decolorizing dye wastewater with Fenton's reagent. Wat. Res. 26(7), 881-886, 1992.

LEUSER, R. M.; VELAZQUEZ, L. A.; COHEN, A.; JANSSEN, J. Remediation of PCB soil contamination by on-site incineration. Journal of Hazardous Materials. 25, 375385, 1990.

LINDSEY, M. E.; TARR, M. A. Inhibited hydroxyl radical degradation of aromatic hydrocarbons in the presence of dissolved fulvic acid. Wat. Res. 34(8), 2385-2389, 2000.

LUNA, A. M.; BRAGA, J. D. A experiência da CHESF no manuseio e armazenamento do óleo ascarel e algumas considerações sobre seu descarte. XIV Seminário Nacional de Produção e Transmissão de Energia Elétrica, Belém - PA, 1997.

PNUMA/UNEP. Desenvolvimento do Plano Nacional de Implementação da Convenção de Estocolmo sobre Poluentes Orgânicos Persistentes no Brasil - NIP Brasil. 2006.

MATTOS, I. L.; SHIRAISHI, K. A.; BRAZ, A. D.; FERNANDES, J. R. Peróxido de hidrogênio: importância e determinação. Quim. Nova. 26(3), 373-380, 2003. 
MESQUITA, A. C. Uso das técnicas de oxidação química e biodegradação na remoção de alguns compostos orgânicos recalcitrantes. 158p. Tese de Doutorado COPPE/UFRJ, Rio de Janeiro, 2004.

MORAES, J. E. F. Aplicação do Processo Foto-Fenton na Degradação de Efluentes Industriais Contendo Poluentes Orgânicos. Tese de Doutorado. São Paulo. 161p. 2003.

NOBRE, M. M.; NOBRE, R. C. M. Remediação de solos - Técnicas alternativas melhoram desempenho. Revista Química e Derivado, edição nº 417, 2003.

NORRIS, G.; AL-DHAHIR, Z.; BIRNSTINGL, J.; PLANT, S. J.; CUI, S.; MAYELL, $P$. A case study of the management and remediation of soil contaminated with polychlorinated biphenyls. Engineering Geology. 53, 177-185, 1999.

OKAWA, K.; SUZUKI, K.; TAKESHITA, T.; NAKANO, K. Degradation of chemical substances using wet peroxide oxidation under mild conditions. Journal of Hazardous Materials. 127, 68-72, 2005.

OTTEN, A.; ALPHENAAR, A.; PIJLS, C.; SPUIJ, F.; DE WIT, H. In Situ Soil Remediation. VOLUME 6. The Netherlands: Kluwer Academic Publishers, 1997.

PENTEADO, J. C. P. Metodologia Analítica para Análise de PCBs em Fígado de Peixe do Rio Paraíba do Sul. 109p. Dissertação de Mestrado - IQ/USP, São Paulo, 2000.

PENTEADO, J. C. P.; VAZ, J. M. O legado das bifenilas policloradas (PCBs). Química Nova. 24(3), 390-398, 2001.

RAHUMAN, M. S. M. M.; PISTONE, L.; TRIFIRÒ, F.; MIERTUS, S. Destruction Technologies for polychlorinated biphenyls (PCBs). ICS-UNIDO Publications, 2000.

RIAZA-FRUTOS, A.; QUIROGA, J. M.; MANZANO, M. A. Remediation of Contaminated Soils with PCBs Using an Integrated Treatment: Desorption and Oxidation. Journal of Enrvironmental Engineering. 541-547, 2007.

RICE, C. P.; O'KEEFE, P. W.; KUBIAK, T. J. Sources, Pathways, and Effects of PCBs, Dioxins, and Dibenzofurans. In: Handbook of Ecotoxicology. 2 ed. CRC Press, 2003.

RISSATO, S. R.; GALHIANE, M. S.; XIMENES, V. F.; ANDRADE, R. M. B.; TALAMONI, J. L. B.; LIBÂNIO, M.; ALMEIDA, M. V.; APON, B. M.; CAVALARI, A. A. Organochlorine pesticides and polychlorinated biphenyls in soil and water samples in the Northeastern part of São Paulo State, Brazil. Chemosphere. 65, 1949-1958, 2006.

RODRIGUEZ, C. P. M. MESQUITA, A. C. Uso das técnicas de oxidação química e biodegradação na remoção de alguns compostos orgânicos recalcitrantes. 158p. Tese de Doutorado - COPPE/UFRJ, Rio de Janeiro, 2004. 80p. Dissertação de Mestrado - PROCAM/USP, São Paulo, 2006. 
SEDLAK, D. L.; ANDREN, A. W. The effect of sorption on the oxidation of polychlorinated biphenyls (PCBs) by hydroxyl radical. Wat. Res. 28, 1207-1215, 1994.

SILVA, D. N.; ZAGATTO, P. J. P.; GUARDANI, R.; NASCIMENTO, C. A. O. Remediação de Solos Contaminados com Linear Alquil Benzenos Usando Reagentes de Fenton. COBEQ, 2004.

SILVA, S. S.; LUNA, A. J.; SILVA, D. N.; CHIAVONE-FILHO, O.; NASCIMENTO, C. A. O. Uso dos Reagentes de Fenton para Remediação de Solos Contaminados com Compostos Fenólicos. COBEQ, 2006.

SPARKS, D. L. Environmental Soil Chemistry. Second Edition. Academic Press, 2003.

SPORRING, S.; BOWADT, S.; SVENSMARK, B.; BJÖRKLUND, E. Comprehensive comparison of classic Soxhlet extraction with Soxtec extraction, ultrasonication extraction, supercritical fluid extraction, microwave assisted extraction and accelerated solvent extraction for the determination of polychlorinated biphenyls in soil. Journal of Chromatography A. 1090, 1-9, 2005.

STOW, J. P. Chemical remediation of PCB contaminated soils using Fenton's reagent. 94p. Dissertação de Mestrado - Kingston, Ontário, 1997.

TANABE, S. PCB Problems in the Future: Foresight from Current Knowledge. Environmental Pollution. 50, 5-28, 1998.

TECORI. Lei $\mathbf{n}^{\circ}$ 12.288, de 22 de fevereiro de 2006. Disponível em: http://www.tecori.com.br/legislacao/lei 12288.html. Acesso em: 05 de setembro. 2006.

TOOGE, C. A. B. Uso do reagente de Fenton como oxidante secundário em sistemas de destruição de resíduos através de oxidação térmica. 157p. Tese de Doutorado - IQ/USP, São Paulo, 2004.

UMWELTBUNDESAMT. Manual for Biological Remediation Techniques. Disponível em: http://www.umweltbundesamt.de/fwbs-e/index.htm. Acesso em: 25 de novembro. 2007.

UNEP. Persistent Organic Pollutants. Disponível em: http://www.chem.unep.ch/pops/default.html. Acesso em: 02 de fevereiro. 2006.

USEPA. Method 3541 - Automated Extraction Soxhlet. USA, 1994.

USEPA. Method 8082A - Polychlorinated Biphenyls (PCBs) by Gas Chromatography. USA, 2000.

VALENTIN, M. M. Laboratory Study of Solvent Extraction of Polychlorinated Biphenyl in Soil. 209p. Dissertação de Mestrado - Montreal, Canadá, 2000.

VILLA, R. D.; NOGUEIRA, R. F. P. Uso de reações de Fenton na remediação de solo contaminado com p,p-DDT. Eclética Química. 30, 69-75, 2006. 
VORHEES, D. J. Polychlorinated biphenyls. In: Indoor Air Quality Handbook. p. 36.136.30. 2004.

VROM. Soil Policy in the Netherlands. Disponível em: http://international.vrom.nl/pagina.html?id=7440. Acesso em: 25 de novembro. 2007.

WANG, Q.; LEMLEY, A. T. Reduced adsorption of ametryn in clay, humic acid, and soil by interaction with ferric ion under Fenton treatment conditions. Journal of Environmental Science and Health Part B. 41, 223-236, 2006.

WATTS, R. J.; KONG, S.; DIPPRE, M.; BARNES, W. T. Oxidation of sorbed hexachlorobenzene in soils using catalyzed hydrogen peroxide. Journal of Hazardous Materials. 39, 33-47, 1994.

WATTS, R. J. In situ application of modified Fenton's reagent spells success for BETX, MTBE site cleanup. Hazardous Waste Consultant. 3, 1998.

WATTS, R. J.; HALLER, D. R.; JONES, A. P.; TEELI, A. L. A foundation for the riskbased treatment of gasoline-contaminated soils using modified Fenton's reactions. Journal of Hazardous Materials B. 76, 73-89, 2000.

WATTS, R. J.; TEEL, A. L. Treatment of contaminated soils and groundwater using ISCO. Practice Periodical of Hazardous, Toxic, and Radioactive Waste Management. 2-9, 2006.

WEINER, E. R. Soil, Groundwater, and Subsurface Contamination. In: Applications of Environmental Chemistry: A Practical Guide for Environmental Professionals. USA: CRC Press, 2000.

WIKIPEDIA. Polychlorinated Biphenyl. Disponível em: http://en.wikipedia.org/wiki/Polychlorinated biphenyl. Acesso em: 22 de novembro. 2007.

YEH, C. K.; KAO, Y.; CHENG, C. Oxidation of clorophenols in soil at natural pH by catalyzed hydrogen peroxide: the effect of soil organic matter. Chemosphere, v. 46, p. 67-73, 2002.

YEH, C. K.; WU, H.; CHEN, T. Chemical oxidation of chlorinated non-aqueous phase liquid by hydrogen peroxide in natural sand systems. Journal of Hazardous Materials B. 96, 29-51, 2003. 